\title{
РЕЗУЛЬТАТЫ МАТЕМАТИЧЕСКОГО МОДЕЛИРОВАНИЯ ПЕРЕХОДНЫХ ПРОЦЕССОВ ДЛЯ УСЛОВИЙ АКВАТОРИЙ МОРСКОГО ШЕЛЬФА
}

\author{
Агеенков Е. В., Ситников А. А., Воднева Е. Н.
}

\begin{abstract}
Аннотация
Электроразведочные измерения на акваториях, как и на суше, проводятся для изучения электромагнитных (ЭМ) свойств геологических образований. Отличительная особенность аквальной электроразведки связана со специфическим влиянием водной толщи.
\end{abstract}

Приведены численные расчёты ЭМ сигнала переходного процесса для электрических линий в осевой области источника в условиях морских акваторий глубиной от 50 до 250 м с целью демонстрации проявления сигнал вызванной поляризации (ВП) в сигнале переходного процесса на разных установках, выявления различий проявления сигналов становления, гальванически и индукционно вызванной поляризации в сигнале переходного процесса и объяснения причин этих различий.

Для изучения влияния размеров установки на проявление ВП во время переходного процесса проанализировано изменение сигнала переходного процесса $(\Delta \mathrm{U}(\mathrm{t}))$, конечной разности сигнала переходного процесса $(\Delta 2 \mathrm{U}(\mathrm{t}))$ и трансформанты P1(t) (отношения этих величин) для горизонтальной электрической установки с источником (АВ) от 50 до 2000 м, 3-х электродной измерительной линией (M1M2М3) от 50 до 2000 м, расстоянием между центрами источника и измерительной линии М1М3 (разносом - r) от 100 до 4000 м. Некоторые из них используются в дифференциально-нормированном методе электроразведки (ДНМЭ). Проведено сравнение $\Delta \mathrm{U}(\mathrm{t})$, $\Delta 2 \mathrm{U}(\mathrm{t})$ и их трансформанты от проводящей и проводящей поляризующейся модели для одинаковых условий. Установка находилась на поверхности и внутри проводящей среды с проводящим поляризующимся основанием. Проводящая среда ассоциировалась с толщей морской воды в шельфовых областях. Проводящее поляризующееся основание - это геологическая среда (земля), перекрытая слоем воды. Учёт поляризуемости основания осуществлён введением частотно зависимого удельного электрического сопротивления посредством формулы Коула Коула.

Выполненные расчёты показывают, что составляющие переходного процесса, связанные со становлением ЭМ поля и с гальванически (ВПГ) и индукционно вызванной поляризацией (ВПИ), по-разному проявляются на установках разных размеров на разных глубинах. ВП для условий акваторий проявляется двояко, связанная как с гальваническим, так и вихревым током. Ранее, при практических измерениях, проявление ВПИ рассматривалось как проявление помех. Но этот сигнал моделируемый и его можно рассматривать как информацию о ВП.

Фактором, влияющим на характер проявления сигнала ВП в сигнале переходного процесса, является приведённая высота установки $(\mathrm{h} \Delta)$ - расстояние между установкой и дном моря (поляризующимся основанием модели) отнесённое к длине АВ (питающей линии). В зависимости от приведённой высоты установки, сигнал ВП в трансформанте P1(t) может проявляться в виде восходящей ветви на поздних временах, а может быть в виде нисходящей ветви, переходящей в отрицательные значения Р1.

Продолжительность импульсного воздействия и измерения переходного процесса сказываются на контрастности проявления поляризующегося основания в сигнале, однако измерения при буксировании установки накладывают ограничения на эти величины. Оптимальные параметры ЭМ съёмки для изучения ВП должны обеспечить присутствие достаточного диапазона для 
регистрации поляризационного сигнала и качество измерений.

Программное обеспечение, использующееся при расчётах, разработано ООО «Сибирская геофизическая научно-производственная компания».

\section{Ключевые слова:}

аквальные электромагнитные зондирования, заземлённая линия, 3-х электродная заземлённая измерительная линия, зондирования проводящих поляризующихся сред на акваториях, модель Коула-Коула, индукционно вызванная поляризация, ВПИ, гальванически вызванная поляризация, ВПГ, прямая задача для проводящей поляризующейся среды 


\title{
РЕЗУЛЬТАТЫ МАТЕМАТИЧЕСКОГО МОДЕЛИРОВАНИЯ ПЕРЕХОДНЫХ ПРОЦЕССОВ ДЛЯ УСЛОВИЙ АКВАТОРИЙ МОРСКОГО ШЕЛЬФА
}

\author{
Е. В. Агеенков ${ }^{1}$, А.А. Ситников ${ }^{2}$, Е.Н. Воднева ${ }^{3}$
}

${ }^{1}$ Институт нефтегазовой геологии и геофизики им. А.А. Трофимука СО РАН, 630090, Новосибирск, просп. Академика Коптюга, 3, Россия

${ }^{2} \mathrm{OOO} \mathrm{«Сибирская} \mathrm{геофизическая} \mathrm{научно-производственная} \mathrm{компания»,} \mathrm{664044,}$ Иркутск, ул. Щапова, 14, Россия

${ }^{3}$ Институт геологии и минералогии им. В.С. Соболева СО РАН, 630090, Новосибирск, просп. Академика Коптюга, 3, Россия

Электроразведочные измерения на акваториях, как и на суше, проводятся для изучения электромагнитных (ЭМ) свойств геологических образований. Отличительная особенность аквальной электроразведки связана со специфическим влиянием водной толщи.

Приведены численные расчёты ЭМ сигнала переходного процесса для электрических линий в осевой области источника в условиях морских акваторий глубиной от 50 до 250 м с целью демонстрации проявления сигнал вызванной поляризации (ВП) в сигнале переходного процесса на разных установках, выявления различий проявления сигналов становления, гальванически и индукционно вызванной поляризации в сигнале переходного процесса и объяснения причин этих различий.

Для изучения влияния размеров установки на проявление ВП во время переходного процесса проанализировано изменение сигнала переходного процесса $(\Delta \mathrm{U}(\mathrm{t}))$, конечной разности сигнала переходного процесса $\left(\Delta^{2} \mathrm{U}(\mathrm{t})\right)$ и трансформанты $\mathrm{P} 1(\mathrm{t})$ (отношения этих величин) для горизонтальной электрической установки с источником (AВ) от 50 до 2000 м, 3-х электродной измерительной линией $\left(\mathrm{M}_{1} \mathrm{M}_{2} \mathrm{M}_{3}\right)$ от 50 до 2000 м, расстоянием между центрами источника и измерительной линии $\mathrm{M}_{1} \mathrm{M}_{3}$ (разносом - r) от 100 до 4000 м. Некоторые из них используются в дифференциально-нормированном методе электроразведки (ДНМЭ). Проведено сравнение $\Delta \mathrm{U}(\mathrm{t}), \Delta^{2} \mathrm{U}(\mathrm{t})$ и их трансформанты от проводящей и проводящей поляризующейся модели для одинаковых условий. Установка находилась на поверхности и внутри проводящей среды с проводящим поляризующимся основанием. Проводящая среда ассоциировалась с толщей морской воды в шельфовых областях. Проводящее поляризующееся основание - это геологическая среда (земля), перекрытая слоем воды. Учёт поляризуемости основания осуществлён введением частотно зависимого удельного электрического сопротивления посредством формулы Коула - Коула.

Выполненные расчёты показывают, что составляющие переходного процесса, связанные со становлением ЭМ поля и с гальванически (ВПГ) и индукционно вызванной поляризацией (ВПИ), по-разному проявляются на установках разных размеров на разных глубинах. ВП для условий акваторий проявляется двояко, связанная как с гальваническим, так и вихревым током. Ранее, при практических измерениях, проявление ВПИ рассматривалось как проявление помех. Но этот сигнал моделируемый и его можно рассматривать как информацию о ВП. 
Фактором, влияющим на характер проявления сигнала ВП в сигнале переходного процесса, является приведённая высота установки $\left(\mathrm{h}_{\Delta}\right)$ - расстояние между установкой и дном моря (поляризующимся основанием модели) отнесённое к длине АВ (питающей линии). В зависимости от приведённой высоты установки, сигнал ВП в трансформанте $\mathrm{P} 1(\mathrm{t})$ может проявляться в виде восходящей ветви на поздних временах, а может быть в виде нисходящей ветви, переходящей в отрицательные значения P1.

Продолжительность импульсного воздействия и измерения переходного процесса сказываются на контрастности проявления поляризующегося основания в сигнале, однако измерения при буксировании установки накладывают ограничения на эти величины. Оптимальные параметры ЭМ съёмки для изучения ВП должны обеспечить присутствие достаточного диапазона для регистрации поляризационного сигнала и качество измерений.

Программное обеспечение, использующееся при расчётах, разработано ООО «Сибирская геофизическая научно-производственная компания».

Ключевые слова: аквальные электромагнитные зондирования, заземлённая линия, 3-х электродная заземлённая измерительная линия, зондирования проводящих поляризующихся сред на акваториях, модель Коула-Коула, индукционно вызванная поляризация, ВПИ, гальванически вызванная поляризация, ВПГ, прямая задача для проводящей поляризующейся среды.

\title{
RESULTS OF MATHEMATICAL MODELING OF TRANSITION PROCESSES FOR THE CONDITIONS OF THE MARINE SHELF AREA
}

\author{
E.V. Ageenkov, A.A. Sitnikov, E.N. Vodneva
}

Electrical exploration measurements in water areas, as well as on land, are carried out to study the electromagnetic (EM) properties of geological formations. A distinctive feature of aquatic electrical prospecting is associated with the specific influence of the water column.The numerical calculations of the EM signal of the transient process for electric lines in the axial region of the source in the conditions of marine waters with a depth of $100 \mathrm{~m}$ are presented.

Numerical calculations of the EM signal of the transient process are presented for electric lines in the axial region of the source under the conditions of sea water areas with a depth of 50 to $250 \mathrm{~m}$ in order to demonstrate the manifestation of the signal of induced polarization (IP) in the signal of the transient process at different installations, to reveal the differences in the manifestation of Inductively Induced Polarization in Transient Signal and Explanations for the Causes of These Differences.

To study the influence of the size of the installation on the manifestation of IP during the transient process, the change in the signal of the transient process $(\Delta U)$, the final difference of the signal of the transient process $\left(\Delta^{2} U\right)$ and the transformants (the ratio of these values) for a horizontal electrical installation with a source (AB) from 50 to $2000 \mathrm{~m}$, 3-electrode measuring line $\left(\mathrm{M}_{1} \mathrm{M}_{2} \mathrm{M}_{3}\right)$ from 50 to $2000 \mathrm{~m}$, the distance between their centers (spacing - r) from 100 to $4000 \mathrm{~m}$. Some of them are used in the differential-normalized method of electrical prospecting (DNME). Comparison of $\Delta \mathrm{U}(\mathrm{t}), \Delta^{2} \mathrm{U}(\mathrm{t})$ and their transformations from the conducting and conducting polarizing models for the same conditions is carried out. The setup was placed on the surface and inside a conducting medium with a conducting polarizable base. The conductive 
polarizing base is the geological medium (earth) covered by a layer of water. The polarizability of the base is taken into account by introducing a frequency-dependent resistivity using the ColeCole formula.

The performed calculations show that the components of the transient process associated with the formation of the EM field and with galvanic (GIP) and induction-induced polarization (IIP), manifest themselves in different ways at installations of different sizes at different depths. The IP for water area conditions manifests itself in two ways, associated with both galvanic and eddy currents. Previously, in practical measurements, the manifestation of IIP was considered as a manifestation of interference. But this signal is simulated and it can be considered as information about the IP.

The factor influencing the character of the IP signal manifestation in the transient signal is the reduced installation height $\left(\mathrm{h}_{\Delta}\right)$ - the distance between the installation and the sea bottom (the polarizing base of the model) referred to the $\mathrm{AB}$ length. Depending on the reduced installation height, the IP signal in the transform P1(t) can manifest itself as an ascending branch at later times, or it may appear as a descending branch that turns into negative values of $\mathrm{P} 1$.

The duration of the impulse action and the measurements of the transient process affect the contrast of the manifestation of the polarizable base in the signal, however, measurements when towing the installation impose restrictions on these values. The optimal parameters of EM survey for studying the IP should ensure the presence of a sufficient range for recording the polarization signal and the quality of measurements.

The software used in the calculations was developed by LLC «Sibirskaya geofizicheskaya nauchno-proizvodstvennaya kompaniya».

Keywords: aquatic electromagnetic sounding, grounded electrical line, tri-electrodes grounded received line, conductive polarizable medium sounding on aquatures, Kole-Kole model, inductive induce polarization, IIP, galvanic induce polarization, GIP, forward modeling for conductive polarizable medium.

\section{ВВЕДЕНИЕ}

Морские акватории, сравнительно, небольшой глубины приурочены, главным образом, к шельфовой части морей. Континентальный шельф (материковая отмель) выровненная часть подводной окраины материка, примыкающая $\mathrm{K}$ суше и характеризующаяся общим с ней геологическим строением. Шельф ограничен берегом моря или океана и резким перегибом поверхности морского дна, связанным с переходом к материковому склону - так называемой бровкой. Глубина над «бровкой» близка к 100-200 м (но в некоторых случаях достигает 500-1500 м, например, у южной части Охотского моря или бровки Новозеландского шельфа) [Леонтьев, 1968].

Материковая отмель Российской Федерации - самая протяжённая в мире, на ней сосредоточено значительное количество природных ресурсов (площадь континентального шельфа, находящегося под юрисдикцией Российской Федерации, включает около 5 млн км$^{2}$, что составляет около 1/5 площади шельфа Мирового океана). Шельф Сибири в Северном Ледовитом океане является самым крупным и наименее изученным из материковых отмелей, регион имеет стратегическое значение благодаря запасам нефти и природного газа [Ибрагимов, Устарханов, 2017].

Проведение электроразведочных работ на шельфе морей направлено на изучение ЭМ свойств геологической среды, находящейся под водным слоем, таких как проводящие 
и поляризационные характеристики. Этот слой, без дополнительного рассмотрения, сильно проводящая однофазная и однородная среда, неполяризующаяся при протекании внешнего тока или возникновении внешнего напряжения. При работах в море имеется ряд выгод для реализации измерений: во-первых, простые условия заземления, во-вторых, возможность осуществлять непрерывную регистрацию сигнала во время буксирования электроразведочной установки, в-третьих, возможность использовать мощные источники питания, большие, по протяжённости, измерительные и питающие линии, транспортировка которых не вызывает трудностей. Интерпретацию полученных результатов упрощает относительная выдержанность ЭМ свойств первого слоя (морской воды), спокойная геоэлектрическая обстановка в верхней части разреза, возможность определения дополнительными измерениям мощности и проводимости водного слоя. Но вместе с тем существует ряд сложностей при проведении морских электроразведочных работ: хорошо проводящий слой морской воды экранирует нижележащие отложения, а гидродинамические процессы, протекающие в нём, приводят $\mathrm{K}$ появлению дополнительных помех [Маловицкий и др., 1977]. На практике осуществлены способы уменьшения влияния такого вида помех на измерения: заглубление и натяжение кабеля косы, увеличение площади измерительных электродов [Ситников и др., 2017], однако эти вопросы, хоть и являются неотъемлемой частью полевых измерений, находятся за рамками описываемого исследования.

Исследуется расчётный сигнал переходного процесса установки с электрическими линиями. Это связано с тем, что источник такой установки легко реализовать технически, поместив заземления в проводящую водную толщу, и без затруднений перемещать его на поверхности или внутри воды. К тому же большая часть аквальных электроразведочных методов использует заземлённую электрическую линию (или диполь) в качестве искусственного ЭМ источника [Sainson, 2017].

Морские электрометрические исследования впервые были проведены в 1931 г. на Каспии в бухте Ильича около Баку и ставили задачу на основе изучения кажущегося сопротивления выявлять выходы коренных пород на дне моря. С этого времени морские электроразведочные работы проводились на Азовском, Каспийском и Чёрном морях. Были разработаны основы методики и техники различных модификаций морской электроразведки с искусственными источниками тока: непрерывных дипольно-осевых зондирований, непрерывного профилирования, дифференциального картировочного электропрофилирования, зондирований становлением магнитного поля, вызванной поляризации [Маловицкий и др., 1977]. При проведении измерений на постоянном токе также использовались установки, измерительные и питающие электроды которых размещались на дне - донные установки [Ваньян, 1956; Терёхин, 1958].

С конца 1970-х и до 1990-х гг. в ПГО «Севморгеология» (г. Ленинград) (ГНПП «Севморгео» (г. Санкт-Петербург)) и в тресте «Южморнефтегеофизика» ПГО «СОЮЗМОРГЕО» (г. Геленджик) разрабатывались методики, аппаратура и оборудование для изучения проводимости и ВП на акваториях. В ПГО «Севморгеология» интенсивно развивался морской аппаратно-методический электроразведочный комплекс зондирования становлением поля с буксируемыми линейными диполями [Вишняков и др., 1983, Вишняков, 1983, Петров, 2000]. В тресте «Южморнефтегеофизика» разрабатывалась технология, позволяющая проводить электроразведочные работы ЗС, ВП и ЕП одновременно с сейсморазведкой методом отражённых волн с борта одного судна [Небрат, 
1990]. Использовались буксируемые симметричные (AMNB) и дипольные (ABMN) установки и донные приёмные линии.

При изучении ВП существенное влияние на измерения оказывает электромагнитная индукция. При измерениях во временной области после выключения тока в течение некоторого времени происходит становление ЭМ поля в земле и для определённых времён наблюдается суперпозиция индукционных и поляризационных эффектов [Уэйт, 1987]. Один из способов уменьшения проявления сигнала индукции в сигнале переходного процесса, при работе в осевой области заземлённой электрической линии (ЗЭЛ) трансформация измерений $3-\mathrm{x}$ электродной измерительной линии $\mathrm{M}_{1} \mathrm{M}_{2} \mathrm{M}_{3}$. Такие измерительные линии и трансформанты используются для изучения ВП при наземных измерениях ДНМЭ [Легейдо, Мандельбаум, Рыхлинский 1995, 1997; Легейдо, 1998; Агеенков, Давыденко, Фомицкий, 2012].

Публикация посвящена аквальному дифференциально-нормированному методу электроразведки (АДНМЭ). Этот метод стал разрабатываться и использоваться с 2000 г. ДГУП «Сибирская геофизическая научно-производственная компания» и ФГУГП «Иркутскгеофизика» под руководством П.Ю. Легейдо [Богданов и др., 2004; Колесов и др., 2008; Veeken et al., 2009a; Veeken et al., 2009б], а позднее, в конце 2000-х гг., его модификация - аквальный дифференциально-нормированный метод электроразведки с подводной буксируемой системой (АДНМЭ с ПБС) [Ситников и др., 2017]. В период с 2002 по 2005 гг. в разработках технологии и проведении полевых работ принимали участие специалисты ПГО «Севморгеология», используя опыт, накопленный ранее.

На акваториях этот метод использует осевые установки с длиной источника от 300 до 1000 м, ряд 3-х электродных измерительных линий от 200 до 600 м с разносом от 600 до 1500 м. На каждой паре измерительных линий $\mathrm{M}_{1} \mathrm{M}_{2} \mathrm{M}_{3}$ проводятся измерения сигнала переходного процесса $\Delta \mathrm{U}(\mathrm{t})(1)$ между электродами $\mathrm{M}_{1}-\mathrm{M}_{3}$ и второй конечной разности сигнала переходного процесса $\Delta^{2} \mathrm{U}(\mathrm{t})(2)$ между электродами $\mathrm{M}_{1}-\mathrm{M}_{2}$ и $\mathrm{M}_{2}-\mathrm{M}_{3}$. Затем, после обработки сигналов $\Delta \mathrm{U}(\mathrm{t})$ и $\Delta^{2} \mathrm{U}(\mathrm{t})$, рассчитывается отношение конечной разности сигнала переходного процесса к сигналу переходного процесса - трансформанта P1(t) на линии $\mathrm{M}_{1} \mathrm{M}_{2} \mathrm{M}_{3}$ (3) [Легейдо, Мандельбаум, Рыхлинский 1995, 1997; Легейдо, 1998].

$$
\begin{gathered}
\Delta U(t)_{M_{1} M_{3}}=\Delta U(t)_{M_{1} M_{2}}+\Delta U(t)_{M_{2} M_{3}} \\
\Delta^{2} U(t)_{M_{1} M_{2} M_{3}}=\Delta U(t)_{M_{1} M_{2}}-\Delta U(t)_{M_{2} M_{3}} \\
P 1(t)_{M_{1} M_{2} M_{3}}=\frac{\Delta^{2} U(t)_{M_{1} M_{2} M_{3}}}{\Delta U(t)_{M_{1} M_{3}}}=\frac{\Delta U(t)_{M_{1} M_{2}}-\Delta U(t)_{M_{2} M_{3}}}{\Delta U(t)_{M_{1} M_{2}}+\Delta U(t)_{M_{2} M_{3}}}
\end{gathered}
$$

$\mathrm{B}$, полученной таким образом трансформанте $\mathrm{P} 1(\mathrm{t})$, в поздней стадии становления в общем сигнале переходного процесса подавляется сигнал, связанный с вихревым током. Поведение $\Delta \mathrm{U}(\mathrm{t}), \quad \Delta^{2} \mathrm{U}(\mathrm{t})$ и $\mathrm{P} 1(\mathrm{t})$ во время переходного процесса для разных геоэлектрических моделей описано в следующем разделе.

Несмотря на большой опыт полевых измерений, выраженный в большом объёме выполненных работ на различных акваториях с целью поисков и разведки УВ, оставались не ясны возможности и ограничения съёмки АДНМЭ с ПБС в движении при использовании разных установок и разной продолжительности импульса тока и времени измерения. 
Целью данного исследования было: продемонстрировать проявление эффекта ВП в сигнале переходного процесса в зависимости от размеров электрических установок, продолжительности импульса тока и времени измерения переходного процесса; выявить различие проявления сигналов становления, гальванически и индукционно вызванной поляризации в сигнале переходного процесса на электрической линии в осевой области источника в условиях акваторий; объяснить причину этих различий.

В ряде ранее опубликованных работ приводились результаты численного моделирования для двух- и трёхслойных поляризующихся моделей в условиях акваторий.

В работе [Вишняков и др., 1988] исследовалось влияние постоянной времени процесса спада ВП нефтегазовых залежей и вмещающих пород на результаты зондирований становлением поля установкой AMNB. Для расчёта поля ВП первичное поле представлялось как сумма единичной ступени, определяющей гальваническое возбуждение, и дельта-функции противоположного знака, описывающей индуктивное возбуждение ВП. Учёт поляризуемости слоёв разреза осуществлялся представлением их удельного электрического сопротивлений в виде комплексных частотно-зависимых величин. Авторы отметили различие знаков сигнала индуктивно и гальванически возбуждённой ВП. Они сделали вывод, что при малой глубине поляризующегося основания влияние переходного поля на процесс спада ВП велико, индуктивно возбуждённая ВП оказывается сильнее, чем возбуждённая гальванически, и на кривых поля ВП появляется интенсивная область отрицательных значений. С увеличением мощности водного слоя, влияние индуктивного возбуждения уменьшается и проявляется на кривой спада ВП в виде локального минимума (без смены знака - прим. авторов).

В публикации [Петров, 2000] приведены результаты моделирования сигнала переходного процесса для симметричной установки, расположенной на поверхности первого слоя (морской воды), и для установки с приёмной линией на поверхности поляризующейся земли. Задача становления поля решена методами линейной цифровой фильтрации, учёт ВП осуществлялся введением частотной дисперсии проводимости формулой Коула-Коула. Показаны изменения сигнала переходного процесса симметричной установки в зависимости от длины генераторной линии и значения постоянной времени ВП. В тексте отмечается дополнительный вклад в токи ВП индукции, возникающей при выключении возбуждающего тока. Автор указал, что при измерениях симметричной установкой сигналы в приёмной линии, связанные с ВП, и чисто электродинамические сигналы имеют разные знаки и в зависимости от сочетания параметров суммарный сигнал может менять знак. Это подтверждалось опытом морских полевых работ - смена знака переходного процесса происходит практически всегда, отметил автор.

Результаты численного моделирования для 3-х электродной установки в контексте проявления сигналов становления, индукционно и гальванически вызванной поляризации для условий Юга Сибирской платформы опубликованы в работе [Агеенков и др., 2020]. Авторы сделали вывод, что для источника заземленная линия в осевой зоне индукционновызванная поляризация может проявляться в смене знака сигнала $\Delta \mathrm{U}(\mathrm{t})$, а для 3-x электродной измерительной установки в смене знака второй конечной разности сигнала переходного процесса $\Delta^{2} \mathrm{U}(\mathrm{t})$ и трансформанты $\mathrm{P} 1(\mathrm{t})$.

В представленном исследовании проведены расчёты переходного процесса $\Delta \mathrm{U}(\mathrm{t})$, конечной разности сигнала переходного процесса $\Delta^{2} \mathrm{U}(\mathrm{t})$ и трансформанты $\mathrm{P} 1(\mathrm{t})$ для разных параметров ЭМ съёмки. Для численного эксперимента принята модель 2-х слойного полупространства. Первый слой, ассоциирующийся с морской толщей, сильно 
проводящий неполяризующийся мощностью 50, 100, 150, 200 и 250 м. Основание геологические образования проводящие поляризующиеся. Исследовалось изменение сигнала при поляризуемости основания 0 и 15\%.

\section{ИЗМЕРЕНИЕ ПЕРЕХОДНОГО ПРОЦЕССА УСТАНОВКОЙ АКВАЛЬНОГО ДИФФЕРЕНЦИАЛЬНО-НОРМИРОВАННОГО МЕТОДА ЭЛЕКТРОРАЗВЕДКИ ПРИ БУКСИРОВАНИИ ЭЛЕКТРОРАЗВЕДОЧНОЙ КОСЫ}

Разъясним поведение измеряемых величин на 3-х электродной установке, расположенной в осевой области ЗЭЛ, на примере двух геоэлектрических моделей. Для одной из них сигнал ВП, главным образом, связан с гальваническим током, для другой с вихревым.

На основе расчётного сигнала переходного процесса между электродами $\mathrm{M}_{1}-\mathrm{M}_{2}$ и $\mathrm{M}_{2}-\mathrm{M}_{3}$ формировался сигнал $\Delta \mathrm{U}(\mathrm{t}), \Delta^{2} \mathrm{U}(\mathrm{t})$ и трансформанта $\mathrm{P} 1(\mathrm{t})$. В такой трансформации величина, дифференцированная в пространстве, будет давать значения отличные от нуля, а распределённая однородно будет иметь нулевые значения.

Рассмотрим, как распределяется в среде вихревой тока и ток гальванически вызванной поляризации вокруг ЗЭЛ. И как эти токи будут растекаться в земле (проникать внутрь земли) во время переходного процесса. Величина плотности тока определяет сигнал переходного процесса $\Delta \mathrm{U}(\mathrm{t})$ на измерительной линии, а пространственная неоднородность плотности тока определяет пространственную дифференциацию ЭМ поля с которой связанна конечная разность сигнала переходного процесса $\Delta^{2} \mathrm{U}(\mathrm{t})$. Рис. 1 показывает, как выглядят графики $\Delta \mathrm{U}(\mathrm{t}), \Delta^{2} \mathrm{U}(\mathrm{t})$ и $\mathrm{P} 1(\mathrm{t})$ над неполяризующейся и поляризующейся землёй при преобладании гальванического возбуждения поляризационных процессов. Для расчётов использовалась осевая установка с длиной источника $(\mathrm{AB})-500$ м, длиной измерительных линий $\left(\mathrm{M}_{1} \mathrm{M}_{2}\right.$ и $\left.\mathrm{M}_{2} \mathrm{M}_{3}\right)$ - по 500 м, разносом (r) - 1250 м и модель полупространства с удельным электрическим сопротивлением (УЭС) 50 Омм. Учёт эффектов вызванной поляризации осуществлён введением частотно зависимого УЭС. Частотная дисперсия УЭС описывалась моделью Коула-Коула (4) [Pelton et al, 1978]:

$$
\rho(\omega)=\rho_{0}\left(1-\eta\left(1-\frac{1}{1+(i \omega \tau)^{c}}\right),\right.
$$

где $\rho_{0}$ - удельное электрическое сопротивление на постоянном токе (Ом`м); $\eta$ коэффициент поляризуемости (доли ед.); $\tau$ - постоянная времени (с); $c$ - показатель степени; $\omega$ - круговая частота $\left(\mathrm{c}^{-1}\right)$.

Во время изменения тока источника в проводящей среде возникает вихревой ток. Для ЗЭЛ в начале переходного процесса структура вихревого тока будет повторять структуру гальванического тока. Процесс становления ЭМ поля связан с растеканием кольца основной плотности вихревых токов вниз и вширь и стремление к равномерному распределению в земле [Strack, 1992]. Поэтому пространственная неоднородность ЭМ поля, связанного с вихревым током, будет уменьшаться, а в поздней стадии становления, стремиться $\mathrm{K}$ нулю. Конечная разность сигнала переходного процесса $\Delta^{2} \mathrm{U}(\mathrm{t})$, обусловленная вихревым током, будет стремиться к нулю в поздней стадии становления. Это показано на рис. 1а, значения $\Delta^{2} \mathrm{U}(\mathrm{t})$ (график 2) резко уменьшаются после времени 0,01 c. 
Гальванический ток, растекаясь в земле с двух заземлений, создаёт потенциальное ЭМ поле, которое, в частности, в осевой области источника уменьшается при удалении от него. Плотность постоянного тока в среде падает при удалении от источника как $1 / \mathrm{r}^{3}$ [Матвеев, 1990]. Протекание тока в многофазной среде приводит к различным механизмам разделения зарядов. После прекращения его течения, геологическая среда начинает возвращаться в первоначальное состояние, возникают токи гальванически вызванной поляризации, которые повторяют распределение в земле токов, вызвавших их и ЭМ поле, созданное ими, также будет сохранять неоднородность в осевой области источника.

Ток ВПГ создаёт ЭМ сигнал, регистрируемый приёмником. Пространственная неоднородность этого тока (и ЭМ отклика, созданного им) сохраняется на протяжении всего переходного процесса и зависит от расстояния до источника. На рис. 1а (график 4) изменения $\Delta^{2} \mathrm{U}(\mathrm{t})$ приобретают другой характер после времени 0,01 с - это объясняется тем, что пространственная неоднородность тока гальванически вызванной поляризации становится больше, чем пространственная неоднородность вихревого тока.

Из-за различий в растекании в земле вихревого тока и тока гальванически вызванной поляризации переходный процесс $\Delta \mathrm{U}(\mathrm{t})$ и $\Delta^{2} \mathrm{U}(\mathrm{t})$ на 3 -х электродной измерительной установке, расположенной в осевой области источника, над неполяризующейся и поляризующейся средой будет существенно различаться (рис. 1a).

Трансформанта $\mathrm{P} 1(\mathrm{t})$, полученная на основе измерений в осевой области заземлённой линии, в поздней стадии становления подавляет составляющую сигнала, связанную с диффузией вихревых токов. В поздней стадии плотность вихревых токов выравнивается в нижнем полупространстве и пространственная неоднородность ЭМ поля, создаваемая вихревым током, стремится к 0. Поэтому на этой стадии переходного процесса трансформанта $\mathrm{P} 1(\mathrm{t})$, для рассмотренных геоэлектрических условий, определяется полем гальванически вызванной поляризации (рис. 1б).

Индукционно вызванная поляризация в осевой области ЗЭЛ проявляется в смене знака $\Delta \mathrm{U}(\mathrm{t})$ [Легейдо, 1998; Моисеев, 2002], а для 3-х электродной измерительной установки в смене знака второй конечной разности сигнала переходного процесса $\Delta^{2} \mathrm{U}(\mathrm{t})$ и трансформанты P1(t) [Агеенков и др., 2020а]. Рис. 2 показывает, как выглядят графики $\Delta \mathrm{U}(\mathrm{t}), \Delta^{2} \mathrm{U}(\mathrm{t})$ и $\mathrm{P} 1(\mathrm{t})$ над неполяризующейся и поляризующейся землёй с преобладанием индукционного возбуждения поляризационных процессов. Для расчётов использовалась, установка, описанная выше, и синтетическая модель, в которой относительно проводящая толща разделена высокоомным экраном, а поляризуемость свойственна только под экранной толще (табл. 1). На первый взгляд, завышенное значение поляризуемости третьего слоя используется для увеличения эффекта ВП, связанного с ним.

Основная плотность гальванического тока, для используемой установки, будет сосредоточена выше высокоомного экрана. Вихревой ток, проникая под высокоомный экран, начинает распространяться под ним и поляризовать среду. По мере затухания вихревого тока, среда возвращается в первоначальное состояние, что сопровождается возникновением тока ВПИ. Этот ток следует «тенью» за вихревым током, но имеет противоположное направление. Пространственная дифференциация тока ВПИ повторяет существовавшую до его возникновения дифференциацию вихревого тока с задержкой во времени.

На графике 4 (рис. 2а) видно, что ВПИ начинает проявляться со времени около 10 мс $-\Delta^{2} U(t)$ начинает уменьшаться вплоть до смены знака сигнала. Это происходит на времени 30 мс, что вызывает смену знака трансформанты. Смена знака $\Delta \mathrm{U}(\mathrm{t})$ (рис. 2а, 
график 2) происходит на времени 500 мс, с этим связана вторая смена знака P1(t), трансформанта становится вновь положительной (рис. 2б, график 6). До времени примерно 1 с значения $\Delta^{2} \mathrm{U}(\mathrm{t})$ превышают значения $\Delta \mathrm{U}(\mathrm{t})$, поэтому трансформанта больше 1 - эта часть графика и большие отрицательные значения не показаны на рис. 2б. Регистрацию сигнала ВПИ, имеющего противоположную полярность, относительно знака сигнала импульса, отмечают при работе с индуктивными установками [Кожевников, 2012; Каменецкий и др. 2014 и мн. др.]. Присутствие смены знака $\Delta \mathrm{U}(\mathrm{t})$ на бо́льших установках при глубине моря около 1000 м отмечалось в измерениях АДНМЭ.

Описанные случаи показывают, как 3-х электродная измерительная линия, расположенная в осевой области ЗЭЛ, позволяет выделить области преобладания сигналов становления, ВПГ и ВПИ во время переходного процесса. Однако нужно подчеркнуть, несмотря на то, что вызванная поляризация возбуждается вихревым или гальваническим током, природа сигнала ВПИ и ВПГ одинакова - электрофизические, электрохимические и электрокинетические релаксационные процессы в многофазной гетерогенной геологической среде.

В АДНМЭ и АДНМЭ с ПБС используется группа 3-х электродных измерительных линий, буксируемых совместно с источником за судном (рис. 3). Такая установка позволяет регистрировать сигнал переходного процесса и конечную разность сигнала переходного процесса, разность потенциалов $\left(\Delta U_{0}\right)$ и вторую конечную разность потенциалов $\left(\Delta^{2} U_{0}\right)$ во время импульса. Измерения проводятся во время буксирования установки, а при обработке сигналов для улучшения соотношения сигнал/помеха проводится пространственное осреднение переходных процессов. Поэтому скорость судна $\left(\mathrm{v}_{\text {судна }}\right)$ во время проведения съёмки и продолжительность импульса $\left(\mathrm{t}_{\text {имп }}\right)$ и времени измерений $\left(\mathrm{t}_{\text {изм }}\right)$ определяют количество измеренных переходных процессов на единицу длины линии съёмки и, в конечном итоге, влияют на качество измерений (табл. 2).

В табл. 2 приведены показатели в зависимости от скорости судна: расстояние, на которое перемещается установка за 1 период токового сигнала ( $\mathrm{L}$ за T, м), и количество периодов токового сигнала на расстоянии 100 и 500 м (Т на $\Delta \mathrm{L}$, шт.). Период токового сигнала (Т) включает 2 токовых импульса разной полярности и 2 продолжительности времени измерения (рис. 3).

При скорости судна 1 м/с ( 2 узла), продолжительности импульса и измерения по 2 с, за один период токового сигнала (8 с) установка сместится на 8 м. При прохождении пути 100 м будет зарегистрировано 26 переходных процессов разной полярности. При скорости судна 2 м/с ( 4 узла), продолжительности импульса и измерения по 16 с, за один период токового сигнала (64 с) установка сместится на 128 м. При прохождении пути 500 м будет зарегистрировано 8 разно полярных переходных процессов.

Осреднённые в пространстве величины $\Delta \mathrm{U}(\mathrm{t}), \Delta^{2} \mathrm{U}(\mathrm{t})$ используются для расчёта трансформанты, которая характеризует ЭМ поле на дистанции осреднения [Ситников и др., 2017].

\section{УСТАНОВКИ ЧИСЛЕННОГО ЭКСПЕРИМЕНТА}

Расчёты сигнала переходного процесса, конечной разности сигнала переходного процесса и трансформанты проведены для ряда установок (рис. 4), их геометрические характеристики приведены в табл. 3. 
Расчёты величин $\Delta \mathrm{U}(\mathrm{t}), \Delta^{2} \mathrm{U}(\mathrm{t})$ и $\mathrm{P} 1(\mathrm{t})$ проведены при различных глубинах расположения установки, она размещалась горизонтально на поверхности моря, в середине водной толщи и на дне акватории - на поверхности геологических образований.

Переходный процесс на интервале времён от 1 мс до 16 с рассчитывался после бесконечного импульса тока (импульс возбуждения - функция Хевисайда или ступень после выключения бесконечно длящегося тока).

Для установки с АВ - 500 м сигнал переходного процесса рассчитывался для разной продолжительности импульса: после бесконечного импульса тока и для продолжительности 2, 4, 8 и 16 с. Время расчёта сигнала начиналось с 1 мс и ограничивалось 16 с при возбуждении бесконечным импульсом, а при конечном импульсе соответствовало продолжительности импульса и составляло 2, 4, 8 и 16 с. При расчётах сигнала от конечного импульса учитывалось влияние трёх предыдущих импульсов разной полярности.

\section{МОДЕЛИ СРЕДЫ}

На акваториях среда представляет из себя особый случай сочетания водной толщи, перекрывающей геологическую среду. В первом приближении её можно аппроксимировать двухслойным полупространством. Верхняя - водная часть проводящая, который зависит от содержания растворённых в воде солей и может достигать 7-2 См/м (0.15-0.5 Ом`м) в морских водоёмах [Основы ..., 1980] и 0.01 См/м (100 Ом·м) в пресноводных водоёмах. Водная толща, в общем случае, однофазна, в ней не возникают процессы ВП. Геологические образования проводящие, представляющиеся двухфазной (полифазной) средой, в которой протекают интенсивные релаксационные процессы, а ЭМ характеристики среды приобретают дисперсионные свойства (зависимость от частоты первичного тока или времени регистрации сигнала). Имеется две границы раздела сред воздух-вода и вода-земля, воздух - непроводящая неполяризующаяся среда, вода - проводящая (для морских акваторий сильно проводящая) неполяризующаяся среда и земля - проводящая поляризующаяся среда. Задачи геоэлектрики - изучение ЭМ свойств геологических образований, которые перекрыты водной толщей разной мощности и проводимости.

Для численного эксперимента были выбраны простые среды - двухслойное полупространство с мощностью воды 50, 100, 150, 200 и 250 м (табл. 4 и 5). Водный слой хорошо проводящий, с УЭС 0,25 Ом·м, неполяризующийся. Проводящие геологические образования - с УЭС 1,5 Ом·м, что свойственно для морских геологических образований, поляризуемость геологической среды была задана 0 или 15 \%. Учёт эффектов ВП при расчётах осуществлён введением частотно зависимого УЭС, описанного моделью КоулаКоула (4).

\section{РАСЧЁТЫ ДЛЯ УСТАНОВОК, НАХОДЯЩИХСЯ НА РАЗНОЙ ГЛУБИНЕ В ВОДНОМ СЛОЕ}

Для демонстрации поведения ЭМ поля, созданного различными по размерам источниками, и сигнала переходного процесса, регистрируемого разными установками, рассмотрим графики трансформанты P1(t) (рис. 5-7) для установок, находящихся на поверхности и в середине водной толщи с глубиной моря 50, 100, 150, 200 и 250 м. Для установок, расположенных на дне акватории рассматриваются разности трансформант $\delta \mathrm{P} 1(\mathrm{t})$ (рис. 8). 
Величина $\delta \mathrm{P} 1(\mathrm{t})$ показывает разность трансформант $\mathrm{P} 1(\mathrm{t})$ во время переходного процесса для проводящей поляризующейся модели и для проводящей модели, рассчитанных для одинаковых условий:

$$
\delta P 1(t)=P 1_{15 \%}(t)-P 1_{0 \%}(t),
$$

где $\mathrm{P} 1_{15 \%}(\mathrm{t})$ - сигнал трансформанты $\mathrm{P} 1(\mathrm{t})$ во время переходного процесса для проводящей поляризующейся модели; $\left.\mathrm{P} 1_{0 \%} \mathrm{t}\right)$ - сигнал трансформанты $\mathrm{P} 1(\mathrm{t})$ во время переходного процесса для проводящей модели. Из-за разного знака трансформанты при проявлении ВПГ и ВПИ $\delta \mathrm{P} 1(\mathrm{t})$ позволяет оценить вклад в сигнал ВП, составляющих связанных с вихревым и гальваническим током. При преобладании в сигнале переходного процесса сигнала ВПИ, $\delta \mathrm{P} 1(\mathrm{t})$ будет отрицательной, при преобладании ВПГ - положительной. Если разность близка к нулю (для поляризующейся модели) - сигналы ВПИ и ВПГ взаимно компенсируют друг друга.

Расчёты для разных установок, погружённых на разные глубины удобно характеризовать значениями толщины водного слоя, отделяющего установку от геологических образований, приведённую к длине источника. Эту величину можно назвать - высота установки над геологическими образованиями, приведённая к длине источника (или приведённая высота установки) (6):

$$
h_{\Delta}=\frac{\Delta h}{A B}=\frac{h_{1}-h_{y c m}}{A B},
$$

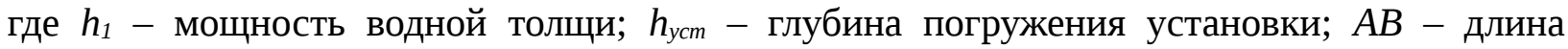
источника установки.

В табл. 6 показаны значения приведённой высоты для установок, использовавшихся при расчётах.

Различие поведения трансформанты (сигнала переходного процесса) для использованных установок можно объяснить, опираясь на оценку эффективной глубины проникновения постоянного тока в проводящей среде. Она изменяется с 1/4 до 1/10 длины источника [Матвеев, 1990], и для сильно проводящих сред (каковой является морская вода) эта величина приближается к меньшим значениям. В морской воде основная плотность гальванического тока сосредоточена вокруг источника в форме, напоминающей эллипсоид вращения с малым радиусом, примерно равным 1/10 длины питающей линии.

Нужно отметить, что на иллюстрациях (рис. 5-7) не показаны графики Р1(t) для установок, расположенных на дне акватории $\left(\mathrm{h}_{\Delta}\right.$ будет равна нулю). В этом случае для всех рассмотренных установок и моделей гальванический ток создаёт в геологической среде высокую плотность, поэтому в сигнале переходного процесса присутствуют сигналы индуктивного становления и ВПГ. Сигнал ВПИ, для рассмотренных моделей, не проявляется при расчётах. Вид трансформанты аналогичен графику 6 (рис. 1б) нисходящая ветвь, минимум значений, восходящая ветвь. Для донных установок их геометрия будет определять продолжительность асимптоты ранней стадии переходного процесса на трансформанте, время минимума и амплитуду P1(t).

Установки, расположенные на поверхности моря, от проводящей поляризующейся геологической среды отделяет вся толща морской воды (50, 100, 150, 200 или 250 м). Приведённая высота будет максимальна для каждой модели и в рассмотренных случаях будет изменяться от 0.125 до 5.

При любой глубине моря, из рассмотренных случаев, источники длиной 2000, 1000 и 500 м во время пропускания тока создают вокруг себя область основной плотности 
гальванического тока с максимальным радиусом в центральной части линии - более 200, 100 и 50 м соответственно (индексы кривых 0.025, 0.075, 0.125; 0.05, 0.15, 0.25 и 0.1, 0.3, 0.5 соответственно на рис. 5a-7a). Гальванический ток высокой плотности будет течь не только в воде, но и в геологической среде, вызывая процессы разделения зарядов. После выключения импульса, распределение ЭМ поля, созданное в стационарном состоянии, некоторое время будет поддерживаться благодаря явлению самоиндукции. После ослабления магнитного поля, противодействующего изменениям, начнётся интенсивный процесс становления поля, сопровождающийся ЭМ сигналом, релаксация геологической среды будет также сопровождаться ЭМ сигналом ВПГ. До времени от сотен мс до нескольких с общий сигнал переходного процесса будет, главным образом, определяться сигналом становления, затем - сигналом ВПГ. Изменение превалирования одной составляющей переходного процесса над другой отмечается в минимуме трансформанты P1(t). Главным образом оно связано с изменением пространственной неоднородности токов и переходом от пространственной неоднородности, определяемой вихревым током, к пространственной неоднородности, определяемой током ВПГ.

Для установок с источником длиной 250 и 100 м эффективная глубина проникновения постоянного тока в сильно проводящей среде - более 25 и 10 м соответственно (индексы кривых 0.2, 0.6, 1 и 0.5, 1.5, 2.5 соответственно на рис 5a-7a) Поэтому такой источник при глубинах акватории более 50 м не создаёт значительную плотность гальванического тока в геологической среде. Во время переходного процесса основная плотность вихревого тока диффундирует сначала в водной толще, а затем в геологической среде. В последней возникает ВП, связанная не с гальваническим, а с вихревым током, которая проявляется на измерителе как ЭМ сигнал противоположного знака и трансформанта приобретает отрицательные значения.

Для установки с длиной источника 50 м эффективная глубина проникновения постоянного тока в сильно проводящей среде - более 5 м (индексы кривых 1, 3, и 5 на рис. 5a-7a), поэтому источник такой длины не создаёт значительную плотность гальванического тока в геологической среде для всех рассматриваемых моделей. Трансформантам для такой установки, в рассматриваемых случаях, характерно присутствие точки разрыва, которая появляется из-за смены знака сигнала $\Delta \mathrm{U}(\mathrm{t})$ (при отрицательных значениях сигнала $\left.\Delta^{2} \mathrm{U}(\mathrm{t})\right)$. P1(t) переходит из отрицательной области в положительную, при этом амплитуда $\Delta^{2} \mathrm{U}(\mathrm{t})$ выше амплитуды $\Delta \mathrm{U}(\mathrm{t})$ и трансформанта приобретает значения больше 1. На поздних временах, в ряде случаев (рис. 6а - индекс кривой 3 и $7 б$ - индекс кривой 2.5), наблюдается асимптотическая ветвь P1(t), которая показывает выравнивание скорости спада сигналов $\Delta \mathrm{U}(\mathrm{t}), \Delta^{2} \mathrm{U}(\mathrm{t})$.

Вид сигналов для установок, погруженных в середину водной толщи (рис. 5б-7б), во многом повторяет расчёты для установок, расположенных на поверхности моря. Главенствующую роль в поведении сигнала так же играет приведённая высота установки.

На рис. 8 объединены представления $\delta \mathrm{P} 1(\mathrm{t})$ для всех моделей, при расположении установки на поверхности моря, в середине водной толщи и на дне акватории. Показаны графики для установок с длиной источника 100 (см. рис. 8а, 8в, 8д) и 500 м (см. рис. 8б, 8г, 8е). Такое представление показывает преобладание индукционной (при отрицательных значениях $\delta \mathrm{P} 1$ ) или гальванической (при положительных значениях $\delta \mathrm{P} 1$ ) составляющей в сигнале ВП. Для установки с длиной источника 50 м графики $\delta \mathrm{P} 1(\mathrm{t})$ близки по виду к графикам для установки с АВ 100 м, только область отрицательных значений начинается с более ранних времён, а для поверхностной установки для всех глубин моря наблюдаются 
отрицательные значения $\delta \mathrm{P} 1$. Графики $\delta \mathrm{P} 1(\mathrm{t})$ для установок с АВ 1000 и 2000 м схожи с представлениями для установки с АВ 500 м - для всех моделей и глубин значения $\delta \mathrm{P} 1$ положительные, лишь снижается амплитуда рассматриваемой величины. Для установки с источником 250 м при расположении её на поверхности большее число графиков $\delta \mathrm{P} 1(\mathrm{t})$ с отрицательными значениями, а при погружении в середину водной толщи преобладают графики в положительной области.

Анализируя визуальные представления результатов расчётов, можно утверждать, что приведённая высота установки определяет вид сигнала ВП, проявляющегося в сигнале переходного процесса. Чем больше высота установки и чем меньше длина источника, тем с большей вероятностью можно ожидать проявление сигнала ВП в виде сигнала ВПИ ( $\mathrm{h}_{\Delta}$ больше 0.5), чем меньше высота установки и чем больше длина источника, тем с большей вероятностью можно ожидать проявление сигнала ВП в виде сигнала ВПГ ( $\mathrm{h}_{\Delta}$ меньше 0.5). Если приведённая высота установки от 0.4 до 0.6, то разность трансформант $\delta \mathrm{P} 1(\mathrm{t})$ имеет низкие значения (близкие к 0 ). Это можно интерпретировать так, что появления ВПГ и ВПИ компенсируют друг друга, то есть сигналы, связанные с токами ВПГ и ВПИ, маскируют друг друга и сигнал ВП становится завуалированным. При изменениях установкой, размещённой на приведённой высоте около 0.5, глубина моря может измениться и привести к появлению аномальных сигналов, связанных с изменением $\mathrm{h}_{\Delta}$ и, в дальнейшем, к неправильной интерпретации результатов измерений. Можно сказать, что расположение установки на уровне приведённой высоты в районе 0.5 является нецелесообразным.

Оптимальным расположением установки для изучения ВП на акваториях можно назвать приведённую высоту больше 0.7 и меньше 0.3. При этом в первом случае ВП будет проявляться на поздних временах переходного процесса в виде смены знака трансформанты (одного или двух), во втором в виде роста её значений после минимума.

\section{РАСЧЁТЫ ДЛЯ РАЗНОЙ ПРОДОЛЖИТЕЛЬНОСТЬЮ ИМПУЛЬСА И ВРЕМЕНИ ИЗМЕРЕНИЯ ПЕРЕХОДНОГО ПРОЦЕССА}

Для установки с длиной источника 500 м (см. рис. 4) сигнал переходного процесса рассчитывался для разной продолжительности импульса, использовалась модель с мощностью водного слоя 100 м.

Результаты исследования представлены в виде графиков P1(t) и $\delta \mathrm{P} 1(\mathrm{t})$ для установки, погруженной на глубину 50 м, для разных форм сигнала (рис. 9).

Главное отличие бесконечно длящегося импульса тока от других рассматриваемых сигналов источника - отсутствие фронта включения, во время которого в среде, окружающей источник, также начинается переходный процесс, а также отсутствие влияния предыдущих импульсов. Практические измерения, использующие последовательность разнополярных токовых импульсов, связаны с регистрацией совокупности переходных процессов, начавшихся в разное время: во время выключения тока в источнике, во время включения тока в источнике, а также во время выключения и включения предыдущих импульсов разной полярности. Сигналы переходных процессов от предыдущих импульсов смещены на продолжительность импульса, продолжительность измерения и импульса и т. д. Сигнал переходного процесса, начавшийся во время выключения тока, имеет знак противоположной полярности относительно знака сигнала, регистрируемого после выключения, поэтому суммарный сигнал уменьшается [Nabighian, 1979; Strack, 1992]. К тому же вихревой ток, распространяющийся в поляризующейся 
среде, будет причиной и сигнала ВПИ - противоположной направленности к поляризующему току. Гальванический ток импульсов разной полярности, соответственно так же будет генерировать токи ВПГ разного направления. Т.о. ослабление совокупного сигнала будет зависеть от удалённости фронта включения импульса и фронтов включения и выключения предыдущих импульсов.

Для рассматриваемых геоэлектрических условий в переходном процессе проявляются сигнал становления и сигнал ВПГ. Минимум трансформанты (см. рис. 9а) свидетельствует о начале преобладания поляризационного сигнала. Чем на более раннем времени отмечен минимум, тем на большем диапазоне времени преобладает поляризационный процесс и тем большую информацию о нём можно получить. В рассмотренном случае на P1(t) от бесконечного импульса минимум проявляется на более раннем времени, чем при конечном времени импульса и учёте сигналов от предыдущих импульсов. Т.о. сигнал ВПГ, возникший во время выключения предыдущего импульса и имеющий противоположный знак, ослабляет сигнал этой же природы, в рассматриваемом переходном процессе. Продолжительность импульсного воздействия и измерения переходного процесса сказываются на контрастности проявления поляризующегося основания в сигнале, однако измерения при буксировании установки накладывают ограничения на эти величины. Оптимальные характеристики сигнала должны обеспечить присутствие достаточного диапазона для регистрации поляризационного сигнала и качество измерений. Для рассматриваемого случая такими являются продолжительность импульса и время измерения в пределах от 4 до 8 с. Используя их разность трансформант (см. рис. 9б) демонстрирует продолжительный временной диапазон проявления сигнала ВПГ от около 300 мс до 4 и 8 с.

\section{ЗАКЛЮЧЕНИЕ}

Расчёты сигналов переходного процесса $\Delta \mathrm{U}(\mathrm{t})$, конечной разности сигнала переходного процесса $\Delta^{2} \mathrm{U}(\mathrm{t})$ и трансформанты P1(t) на разных по размерам установках, погруженных в водный слой при его мощности от 50 до 250 м, показали зависимость характера проявления сигнала ВП в сигнале переходного процесса от приведённой высоты установки $\left(\mathrm{h}_{\Delta}\right)$. Это толщина водного слоя, отделяющего установку от геологических образований, приведённая к длине источника.

Для условий акваторий сигнал ВП, связанный с гальваническим и вихревым током, двояко проявляется в сигнале переходного процесса, в значениях второй конечной разности сигнала переходного процесса и их трансформанте. Ранее, при практических измерениях, проявление ВПИ рассматривалось как проявление помех. Но этот сигнал моделируемый и его можно рассматривать как информацию о ВП. В зависимости от приведённой высоты установки, сигнал ВП в трансформанте P1(t) может проявляться в виде восходящей ветви на поздних временах, а может быть в виде нисходящей ветви, переходящей в отрицательные значения Р1.

Оптимальным расположением установки для изучения ВП на акваториях можно назвать приведённую высоту больше 0.7 и меньше 0.3. При этом, в первом случае, ВП будет проявляться на поздних временах переходного процесса в виде смены знака трансформанты (один или два раза), во втором - в виде роста её значений после минимума. Размещение установки для изучения ВП геологических образований на приведённой высоте 0.5 является нецелесообразным из-за взаимного подавления сигналов ВПИ и ВПГ. 
Для расчётов с разной продолжительностью импульса, по виду кривых $\Delta \mathrm{U}(\mathrm{t})$, $\Delta^{2} \mathrm{U}(\mathrm{t}), \mathrm{P} 1(\mathrm{t})$ и расхождению $\delta \mathrm{P} 1(\mathrm{t})$, видно преимущество более продолжительных импульсов и регистрация сигнала до больших времён, что традиционно в методах становления. Однако для практических измерений, проходящих при буксировании установки, продолжительность времени импульсов и времени измерений влияет на количество измеренных переходных процессов на единице длины линии профиля. Соответственно, приходится ограничивать время импульса и измерений, чтобы улучшить возможности статистического выделения полезного сигнала на фоне помех. Но эти ограничения, в то же время, должны позволить зарегистрировать проявление процесса ВП в общем сигнале.

Исследовано проявление сигнала ВП во время переходного процесса для 2-х слойного полупространства с поляризующимся основанием. Сделаны выводы об оптимальной глубине расположения установки внутри водной толщи и продолжительности импульсного воздействия и регистрации сигналов. Дальнейшие исследования целесообразно продолжить для моделей слоистых сред, отражающих различные физико-геологические модели, и определить оптимальные параметры ЭМ съёмки, которые в каждом случае будут связаны с поставленной геологической задачей.

Авторы благодарны рецензенту публикации д.ф.-м.н., доценту, г.н.с. ИНГГ СО РАН Е.Ю. Антонову за кропотливую работу при рецензировании статьи и ценные советы по улучшению её структуры и содержания. Д.г.-м.н., профессору, г.н.с. ИНГГ СО РАН Н.О. Кожевникову за ценные советы и обсуждение исследования. А так же неизвестному рецензенту за его советы и рекомендации.

Работа выполнена при поддержке программы ФНИ №0331-2019-0007.

\section{ЛИТЕРАТУРА}

Агеенков Е.В., Давыденко Ю.А., Фомицкий В.А. Влияние неосевого расположения приёмной и птьающей электрических линий на результаты дифференциальнонормированного метода электроразведки // Геология и геофизика. 2012. Т. 53. № 1. С. 150 157.

Агеенков Е.В., Ситников А.А., Пестрев И.Ю., Попков А.В. О проявлении процессов индукционного становления и вызванной поляризации при работе с осевой и симметричной электрическими установками // Геология и геофизика. 2020a. Т. 61. № 7. С. 976-991. https://doi.org/10.15372/GiG2019151.

Агеенков Е.В., Воднева Е.Н., Ситников А.А. Влияние продолжительности импульса и времени измерения переходного процесса на проявление низкочастотной дисперсии электромагнитных свойств земли в измерениях на акваториях с глубиной до 100 м. Науки о Земле и недропользование. 2020б. Т. 43. № 1. С. 49-58. https://doi.org/10.21285/26869993-2020-43-1-49-58

Богданов А.Г., Кобзарев Г.Ю., Делия С.В., Зеленцов В.В., Иванов С.А., Легейдо П.Ю., Мандельбаум М.М. Опыт применения и геологические результаты работ дифференциальным нормированным методом электроразведки на российской акватории Каспийского моря // Геофизика. - 2004. - №5. - С.38-41.

Ваньян Л.Л. О теоретических кривых морского электрического зондирования донной установкой // Прикладная геофизика. - 1956. - Вып. 15. - С. 83-90.

Вишняков А.Э., Богородский М.М., Паняев В.П., Яневич М.Ю. Методика, технология и аппаратура морских электроразведочных работ при прямых поисках нефти и газа // Аппаратура и исследования геомагнитного поля. - М. : ИЗМИРАН, 1983. - с. 110117. 
Вишняков А.Э. Методика морских электроразведочных работ с целью прямых поисков нефтегазовых залежей // Рациональный комплекс морских геофизических исследований. - Л. : Изд. ПГО «Севморгелогия», 1983. - с. 89-96.

Вишняков А.Э., Лисицын Е.Д., Яневич М.Ю. Влияние временных параметров вызванной поляризации залежей углеводородов на переходные процессы электромагнитного поля // Техника и методика геофизических исследований Мирового океана. Сборник научных трудов - 1988, с. 124-132.

Ибрагимов А.М., Устарханов У.Н. Территориальные претензии арктических государств на континентальный шельф Арктики // Юридический вестник Дагестанского государственного университета. 2017. Т. 24. № 4. С. 104-108.

Каменецкий Ф.М., Тригубович Г.М., Чернышёв А.В. Три лекции о вызванной поляризации геологической среды. - Мюнхен : Вела Ферлаг, 2014. - 58 с.

Кожевников Н.О. Быстропротекающая индукционно-вызванная поляризация в мёрзлых породах // Геология и геофизика, 2012, т. 53, № 4, с. 527-540.

Колесов В.В., Вовк В.С., Дзюбло А.Д., Кудрявцева Е.О. Разведка и обустройство месторождений в прибрежной зоне Обской губы // Газовая промышленность. - 2008. №12. - С.66-68.

Леонтьев О.К. Дно океана. М.: Мысль, 1968. 320 с.

Легейдо П.Ю., Мандельбаум М.М., Рыхлинский Н.И. Дифференциальнонормированный метод электроразведки при прямых поисках залежей углеводородов // Геофизика, 1995, № 4, с. 42-45.

Легейдо П.Ю., Мандельбаум М.М., Рыхлинский Н.И. Информативность дифференциальных методов электроразведки при изучении поляризующихся сред // Геофизика, 1997, №3, с. 49-56.

Легейдо П.Ю. Теория и технология дифференциально-нормированной геоэлектроразведки для изучения поляризующихся разрезов в нефтегазовой геофизике: дис. ... д-ра геолог.-минералог. наук: 04.00.12. Иркутск, 1998. 198 с.

Маловицкий Я.П., Гагельганц А.А., Коган Л.И. и др. Морские геофизические исследования. М.: Недра, 1977. 375 с.

Матвеев Б.К. Электроразведка. - М. : Недра, 1990. - 368 с.

Моисеев В.С. Метод вызванной поляризации при поисках нефтеперспективных площадей. Новосибирск, Наука, 2002, 136 с.

Небрат А.Г. Интерпретация данных ЗСБ в морских условиях: автореф. дис. ... к-та геолог.-минералог. наук: 04.00.12. Москва, 1990. 198 с.

Основы морской электроразведки / Под ред. Н.И. Калашников, Ф.Л. Дудкин, Ю.Б. Николаенко - К.: Наука думка, 1980. - 208 с. Стр. 125-126.

Петров А.А. Возможности метода становления электрического поля при поисках углеводородов в шельфовых зонах // Геофизика, 2000, №5, с. 21-26.

Ситников А.А., Иванов С.А., Жуган П.П., Мальцев С.Х., Агеенков Е.В. Аппаратура, устройства и системы наблюдений для решения нефтегазопоисковых и инженерногеологических задач на акваториях электроразведочными методами ДНМЭ и НДЭМЗ // Приборы и системы разведочной геофизики. - 2017. - №2. - С. 34-41.

Терёхин Е.И. Теоретические основы электрического зондирования с установкой, погружённой в воду // Прикладная геофизика. - 1958. - Вып. 18. - С.78-102.

Уэйт Дж.Р. Геоэлектромагнетизм. М.: Недра, 1987. 235 с.

Nabighian M.N. Quasi-static transient response of a conducting half-space: An approximate representation // Geophysics, 1979, 44, p. 1700-1705.

Pelton W.H., Ward S.H., Hallof P.G., Sill W.R., Nelson P.H. Mineral discrimination and removal of inductive coupling with multifre-quency IP // Geophysics - 1978. - 43. - P.588-609.

Sainson S. Electromagnetic Seabed Logging. Springer International Publishing, Switzerland 2017. p. 549. ISBN 978-3-319-45353-8 ISBN 978-3-319-45355-2 (eBook) DOI 0.1007/978-3-319-45355-2. 
Strack K.-M. Exploration with deep transient electromagnetics. - Elsevier science publishing Co, 1992. - 373 p.

Veeken P., Legeydo P., Pesterev I., Davidenko Y., Kudryavceva E., Ivanov S. Geoelectric modelling with separation between electromagnetic and induced polarization field components // First break. - 2009a - Vol. 27, December. - P.53-64.

Veeken P., Legeydo P., Davidenko Y., Kudryavceva E., Ivanov S., Chuvaev A. Benefits of the induced polarization geoelectric method to hydrocarbon exploration // Geophysics - 2009б. 74. - P.47-59. 
Рис. 1. Решение ЭМ прямой задачи в осевой области ЗЭЛ: а). сигнал переходного процесса $(\Delta \mathrm{U}(\mathrm{t}))$ и конечная разность сигнала переходного процесса $\left(\Delta^{2} \mathrm{U}(\mathrm{t})\right)$; б). трансформанта P1(t). Обозначения графиков: 1 и $3-\Delta \mathrm{U}(\mathrm{t}) ; 2$ и $4-\Delta^{2} \mathrm{U}(\mathrm{t}) ; 5$ и $6-\mathrm{P} 1(\mathrm{t})$ над неполяризующейся $(\eta=0)$ и поляризующейся $(\eta=5 \%)$ землёй, соответственно (По Легейдо, 1998).

Рис. 2. Решение ЭМ прямой задачи в осевой области ЗЭЛ: а). сигнал переходного процесса $(\Delta \mathrm{U}(\mathrm{t}))$ и конечная разность сигнала переходного процесса $\left(\Delta^{2} \mathrm{U}(\mathrm{t})\right)$; б). трансформанта P1(t). Обозначения графиков: 1 и $3-\Delta \mathrm{U}(\mathrm{t}) ; 2$ и $4-\Delta^{2} \mathrm{U}(\mathrm{t}) ; 5$ и $6-\mathrm{P} 1(\mathrm{t})$ над неполяризующейся $(\eta=0)$ и поляризующейся в подэкранной толще $(\eta=50 \%)$ землёй, соответственно (По Агеенков и др., 2020а).

Рис. 3. Установка АДНМЭ: А и В - питающие электроды, $\mathrm{M}_{1}-\mathrm{M}_{7}$ - измерительные электроды.

Рис. 4. Схемы электрических установок, использовавшихся при расчётах

Рис. 5. Трансформанта P1(t) для установок: а - находящихся на поверхности моря; б - в середине водной толщи при глубине моря 50 м. Обозначения графиков для установок с длиной источника: 1 - 50 м; 2 - 100 м; 3 - 250 м; $4-500$ м; 5 - 1000 м; 6 - 2000 м; 7 графики для проводящей неполяризующейся модели. Индексы кривых - приведённая высота установки.

Рис. 6. Трансформанта P1(t) для установок: а - находящихся на поверхности моря; б - в середине водной толщи при глубине моря 150 м. Усл. обозн. см. на рис. 5.

Рис. 7. Трансформанта P1(t) для установок: a - находящихся на поверхности моря; б - в середине водной толщи при глубине моря 250 м. Усл. обозн. см. на рис. 5

Рис. 8. Разность трансформант $\delta \mathrm{P} 1(\mathrm{t})$ для установок с длиной источника 100 и 500 м, расположенных на поверхности акватории (а и б), в середине водного слоя (в и г) и на дне акватории (д и е) соответственно, при глубинах моря 50, 100, 150, 200 и 250 м. Индексы кривых - приведённая высота установки. Сплошными линиями показаны положительные значения, пунктиром - отрицательные.

Рис. 9. Расчёты, сделанные для установки с АВ - 500 м, погруженной на глубину 50 м при глубине моря 100 м, от проводящей поляризующейся модели для разной продолжительности импульса и измерительной паузы: а - трансформанта P1(t); б разность трансформант $\delta \mathrm{P} 1(\mathrm{t})$. Обозначения графиков для разной продолжительности импульса и измерительной паузы: 1 - 2 с и 2 с; 2 - 4 с и 4 с; $3-8$ с и 8 с; $3-16$ с и 16 с; $4-$ бесконечный импульс тока, 16 с измерительная пауза. 
Табл. 1

Модель среды с преобладанием индукционного возбуждения поляризационных процессов

\begin{tabular}{|l|l|l|l|l|l|}
\hline $\begin{array}{l}\text { Сло } \\
\text { й }\end{array}$ & $\rho$, Ом·м & $\begin{array}{l}\eta, \\
\%\end{array}$ & $\begin{array}{l}\text { т, } \\
\text { с }\end{array}$ & $\begin{array}{l}\text { с, } \\
\text { б.p. }\end{array}$ & $\begin{array}{l}\text { h, } \\
\text { м }\end{array}$ \\
\hline 1 & 50 & 0 & & & 300 \\
\hline 2 & 1000 & 0 & & & 500 \\
\hline 3 & 50 & 50 & 1 & 0.5 & $\infty$ \\
\hline
\end{tabular}


Табл. 2

Расстояние, на которое перемещается установка за 1 период токового сигнала и количество периодов токового сигнала на расстоянии 100 и 500 м в зависимости от скорости судна

\begin{tabular}{|c|c|c|c|c|}
\hline $\mathrm{V}_{\text {судна, }} \mathrm{M} / \mathrm{C}$ & $\mathrm{T}, \mathrm{C}$ & L за T, м & $\Delta \mathrm{L}, \mathrm{M}$ & T на $\Delta \mathrm{L}$, шт. \\
\hline \multirow{6}{*}{1} & \multirow{2}{*}{8} & \multirow{2}{*}{8} & 100 & 13 \\
\hline & & & 500 & 61 \\
\hline & \multirow{2}{*}{16} & \multirow{2}{*}{16} & 100 & 6 \\
\hline & & & 500 & 30 \\
\hline & \multirow{2}{*}{64} & \multirow{2}{*}{64} & 100 & 2 \\
\hline & & & 500 & 8 \\
\hline \multirow{6}{*}{2} & \multirow{2}{*}{8} & \multirow{2}{*}{16} & 100 & 6 \\
\hline & & & 500 & 31 \\
\hline & \multirow{2}{*}{16} & \multirow{2}{*}{32} & 100 & 3 \\
\hline & & & 500 & 16 \\
\hline & \multirow{2}{*}{64} & \multirow{2}{*}{128} & 100 & 0,8 \\
\hline & & & 500 & 4 \\
\hline
\end{tabular}


Табл. 3

Геометрические характеристики установок, использовавшиеся для расчётов

\begin{tabular}{|l|l|l|l|}
\hline № установки & $\begin{array}{l}\text { Длина источника } \\
(\mathrm{AB}), \mathrm{M}\end{array}$ & $\begin{array}{l}\text { Длина } \\
\text { измерительных } \\
\text { линий } \\
\left.\mathrm{M}_{2} \mathrm{M}_{3}\right), \mathrm{M}\end{array}$ & Разнос (r), м \\
\hline 1 & 50 & 25 & 100 \\
\hline 2 & 100 & 50 & 200 \\
\hline 3 & 250 & 150 & 500 \\
\hline 4 & 500 & 250 & 1000 \\
\hline 5 & 1000 & 500 & 2000 \\
\hline 6 & 2000 & 1000 & 4000 \\
\hline
\end{tabular}


Табл. 4

Модель проводящей среды

\begin{tabular}{|l|l|l|l|}
\hline Слой & $\rho$, Ом·м & $\eta, \%$ & h, м \\
\hline 1 & 0.25 & 0 & $\begin{array}{l}50,100, \quad 150, \\
200,250\end{array}$ \\
\hline 2 & 1.5 & 0 & $\infty$ \\
\hline
\end{tabular}


Табл. 5

Модель проводящей среды с поляризующимся основанием

\begin{tabular}{|l|l|l|l|l|l|}
\hline Слой & $\rho$, Ом·м & $\eta, \%$ & т, с & с, б.р. & h, м \\
\hline 1 & 0.25 & 0 & & & $\begin{array}{l}50,100,150, \\
200,250\end{array}$ \\
\hline 2 & 1.5 & 15 & 0.5 & 0.5 & $\infty$ \\
\hline
\end{tabular}


Табл. 6.

Приведённая высота установки над поляризующимся основанием

\begin{tabular}{|c|c|c|c|c|c|}
\hline № пா & $\begin{array}{l}\text { Длина } \\
\text { источника } \\
\text { (AB), м } \\
\end{array}$ & $\begin{array}{l}\text { Мощность } \\
\text { водного слоя }\left(\mathrm{h}_{1}\right) \text {, } \\
\text { м }\end{array}$ & $\begin{array}{l}\text { Глубина погружения } \\
\text { установки (hyсr), м }\end{array}$ & $\begin{array}{l}\text { Приведённая } \\
\text { установки }\left(\mathrm{h}_{\Delta}\right)\end{array}$ & высота \\
\hline \multirow{5}{*}{1} & \multirow{5}{*}{50} & 50 & $0,25,50$ & $1,0.5,0$ & \\
\hline & & 100 & $0,50,100$ & $2,1,0$ & \\
\hline & & 150 & $0,75,150$ & $3,1.5,0$ & \\
\hline & & 200 & $0,100,200$ & $4,2,0$ & \\
\hline & & 250 & $0,125,250$ & $5,2.5,0$ & \\
\hline \multirow{5}{*}{2} & \multirow{5}{*}{100} & 50 & $0,25,50$ & $0.5,0.25,0$ & \\
\hline & & 100 & $0,50,100$ & $1,0.5,0$ & \\
\hline & & 150 & $0,75,150$ & $1.5,0.75,0$ & \\
\hline & & 200 & $0,100,200$ & $2,1,0$ & \\
\hline & & 250 & $0,125,250$ & $2.5,1.25,0$ & \\
\hline \multirow{5}{*}{3} & \multirow{5}{*}{250} & 50 & $0,25,50$ & $0.2,0.1,0$ & \\
\hline & & 100 & $0,50,100$ & $0.4,0.2,0$ & \\
\hline & & 150 & $0,75,150$ & $0.6,0.3,0$ & \\
\hline & & 200 & $0,100,200$ & $0.8,0.4,0$ & \\
\hline & & 250 & $0,125,250$ & $1,0.5,0$ & \\
\hline \multirow{5}{*}{4} & \multirow{5}{*}{500} & 50 & $0,25,50$ & $0.1,0.05,0$ & \\
\hline & & 100 & $0,50,100$ & $0.2,0.1,0$ & \\
\hline & & 150 & $0,75,150$ & $0.3,0.15,0$ & \\
\hline & & 200 & $0,100,200$ & $0.4,0.2,0$ & \\
\hline & & 250 & $0,125,250$ & $0.5,0.25,0$ & \\
\hline \multirow{5}{*}{5} & \multirow{5}{*}{1000} & 50 & $0,25,50$ & $0.05,0.025,0$ & \\
\hline & & 100 & $0,50,100$ & $0.1,0.05,0$ & \\
\hline & & 150 & $0,75,150$ & $0.15,0.075,0$ & \\
\hline & & 200 & $0,100,200$ & $0.2,0.1,0$ & \\
\hline & & 250 & $0,125,250$ & $0.25,0.125,0$ & \\
\hline \multirow{5}{*}{6} & \multirow{5}{*}{2000} & 50 & $0,25,50$ & $0.025,0.0125,0$ & \\
\hline & & 100 & $0,50,100$ & $0.05,0.025,0$ & \\
\hline & & 150 & $0,75,150$ & $0.075,0.0375,0$ & \\
\hline & & 200 & $0,100,200$ & $0.1,0.05,0$ & \\
\hline & & 250 & $0,125,250$ & $0.125,0.0625,0$ & \\
\hline
\end{tabular}




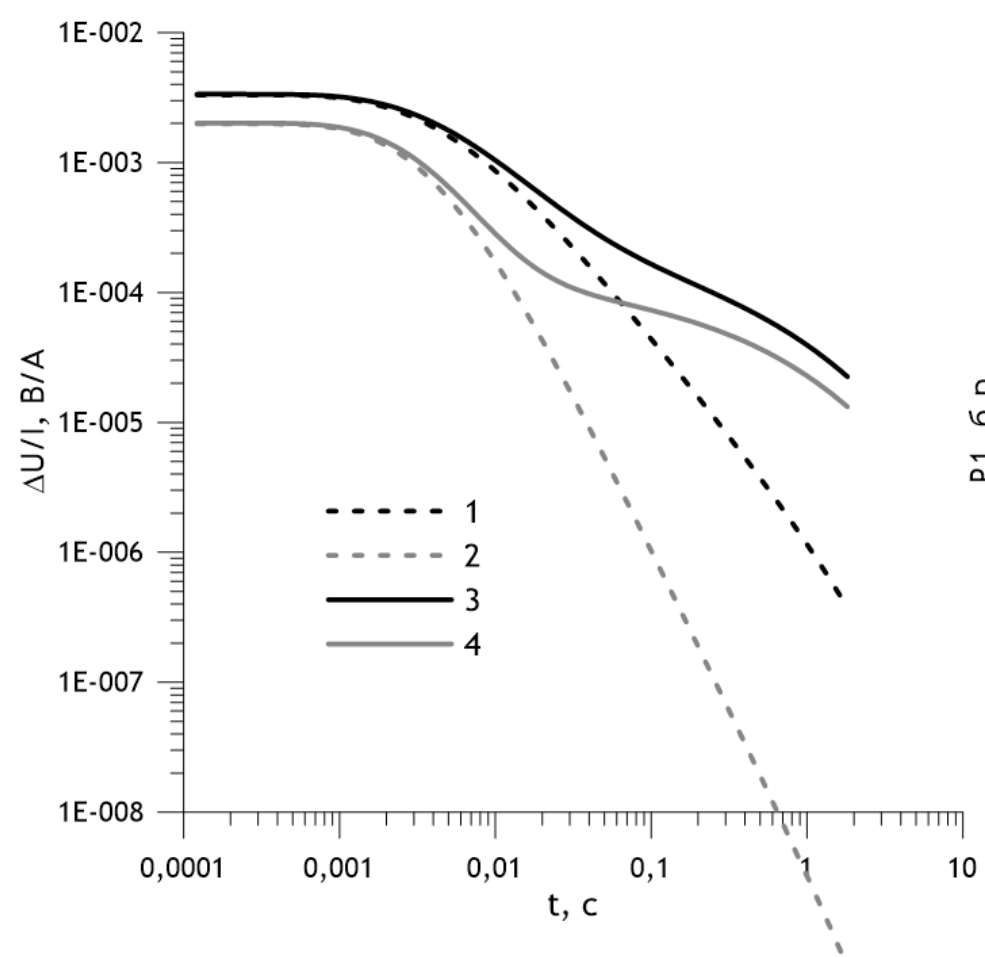

a).

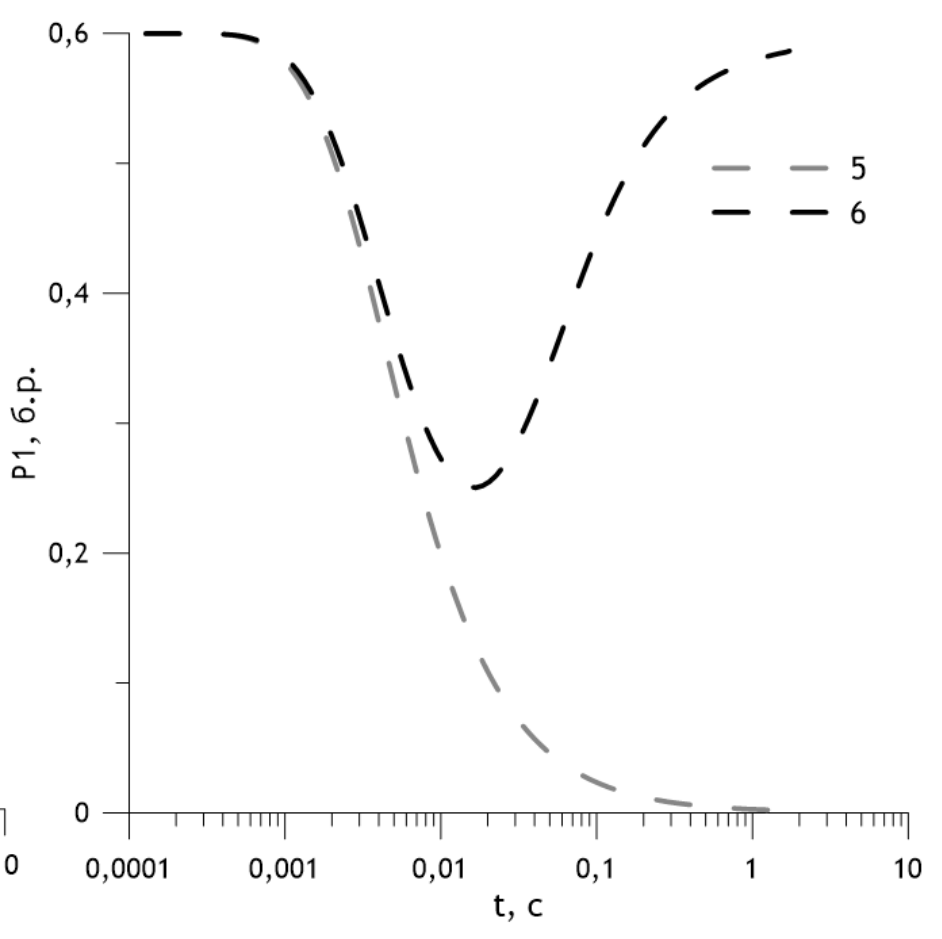

б). 


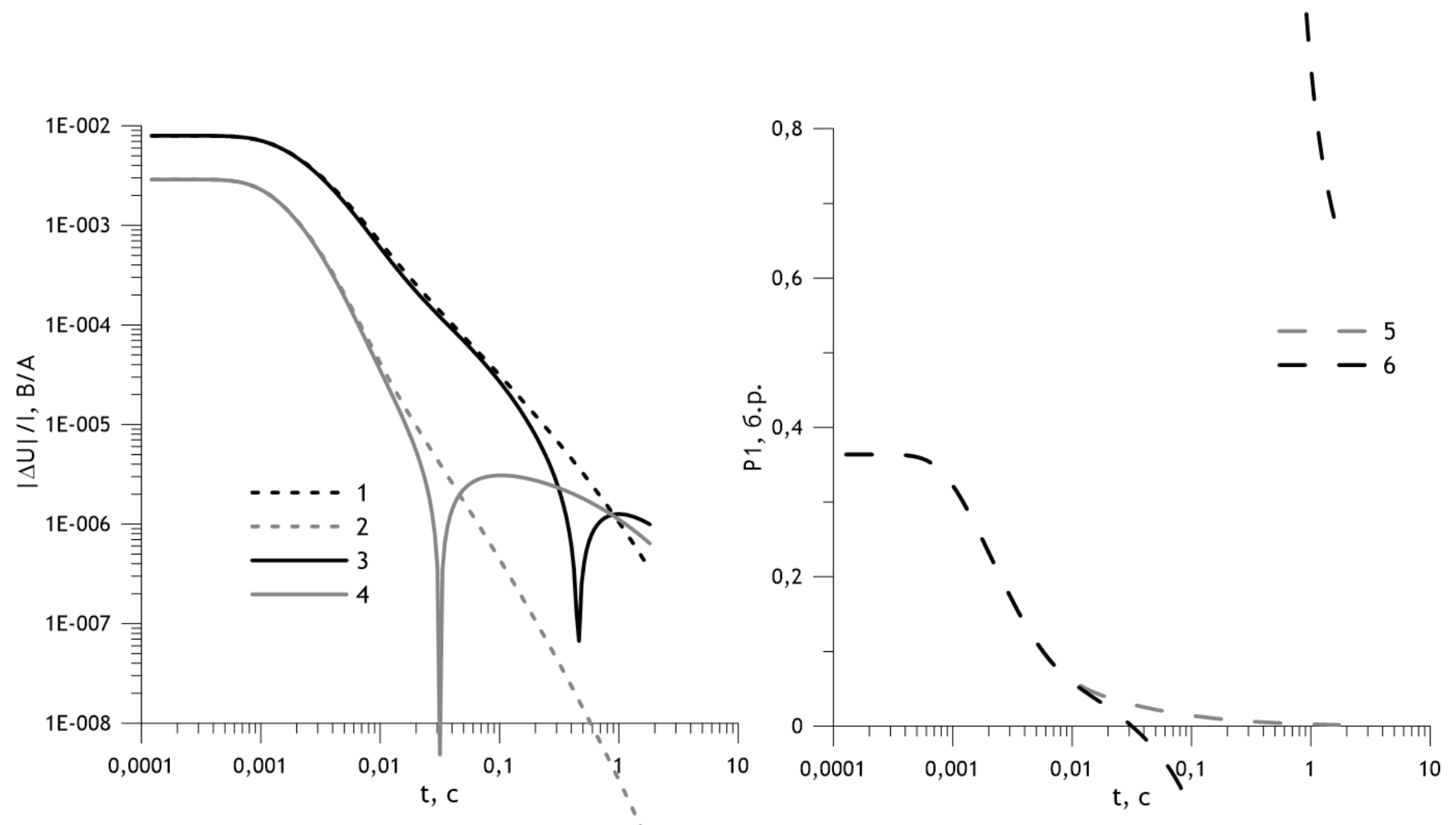

a).

б). 
II

A 
Масштаб: 1 см - 10 м

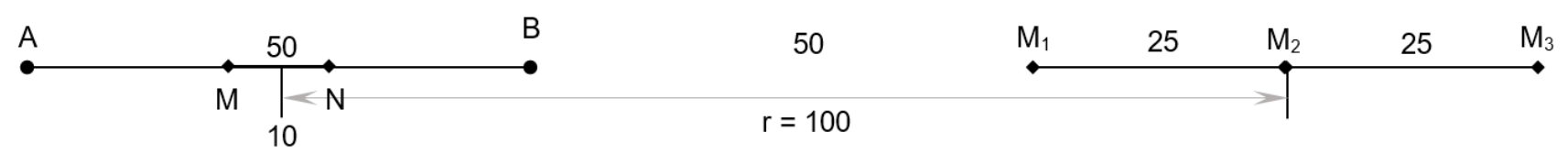

Масштаб: 1 см - 100 м
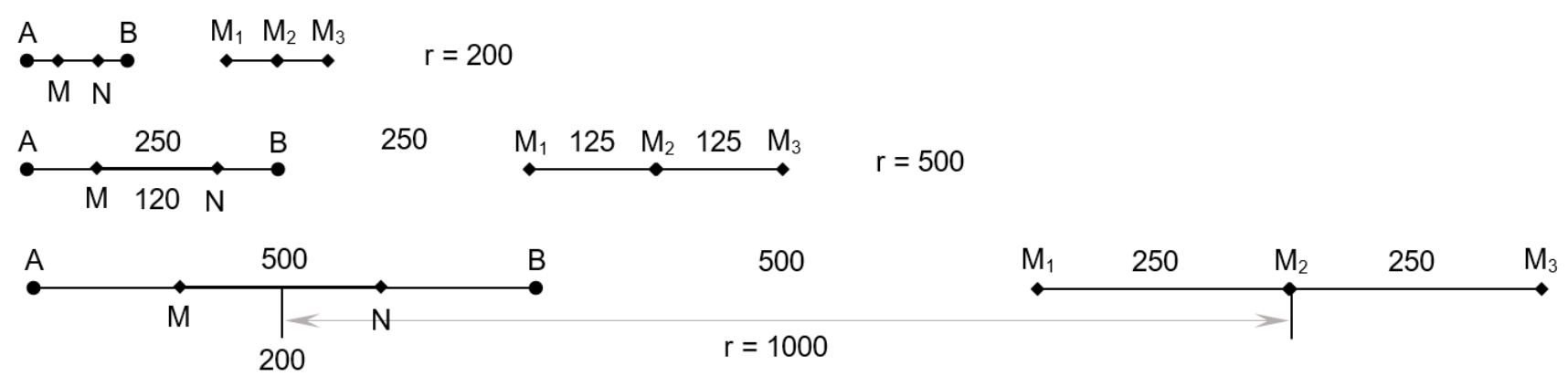

Масштаб: 1 см - 1000 м
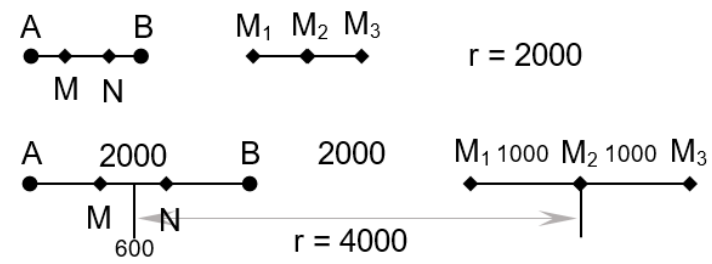

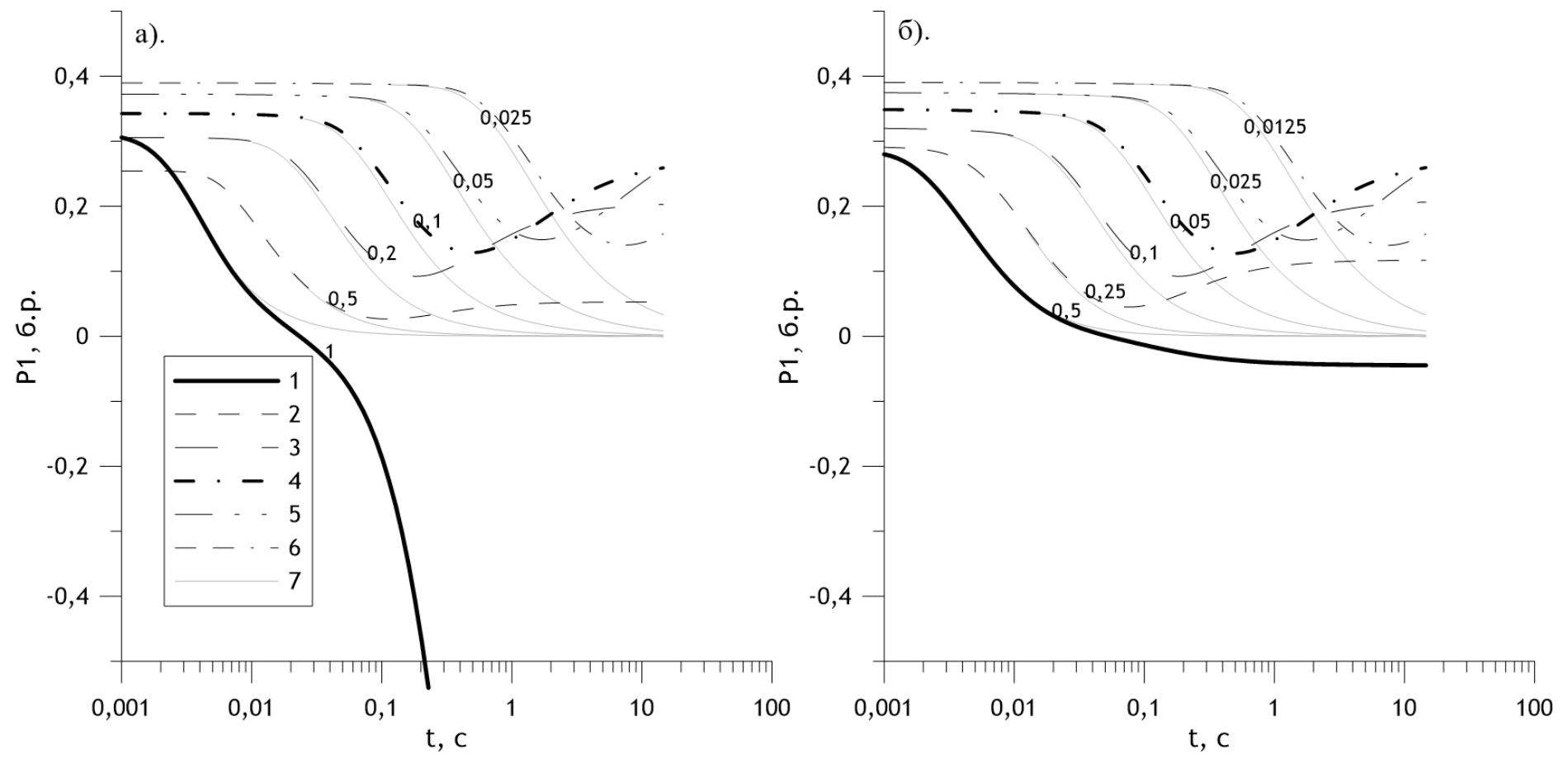


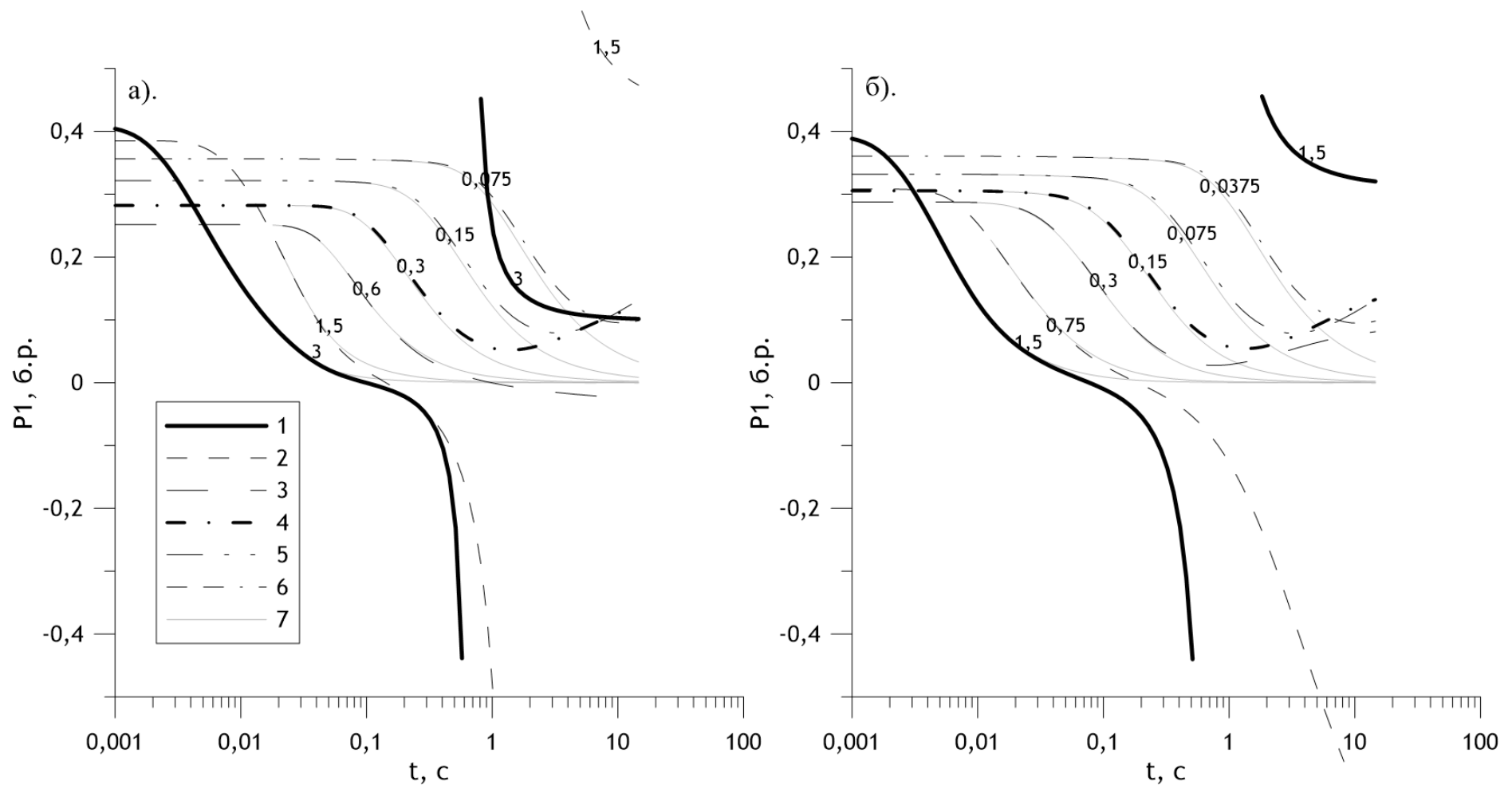



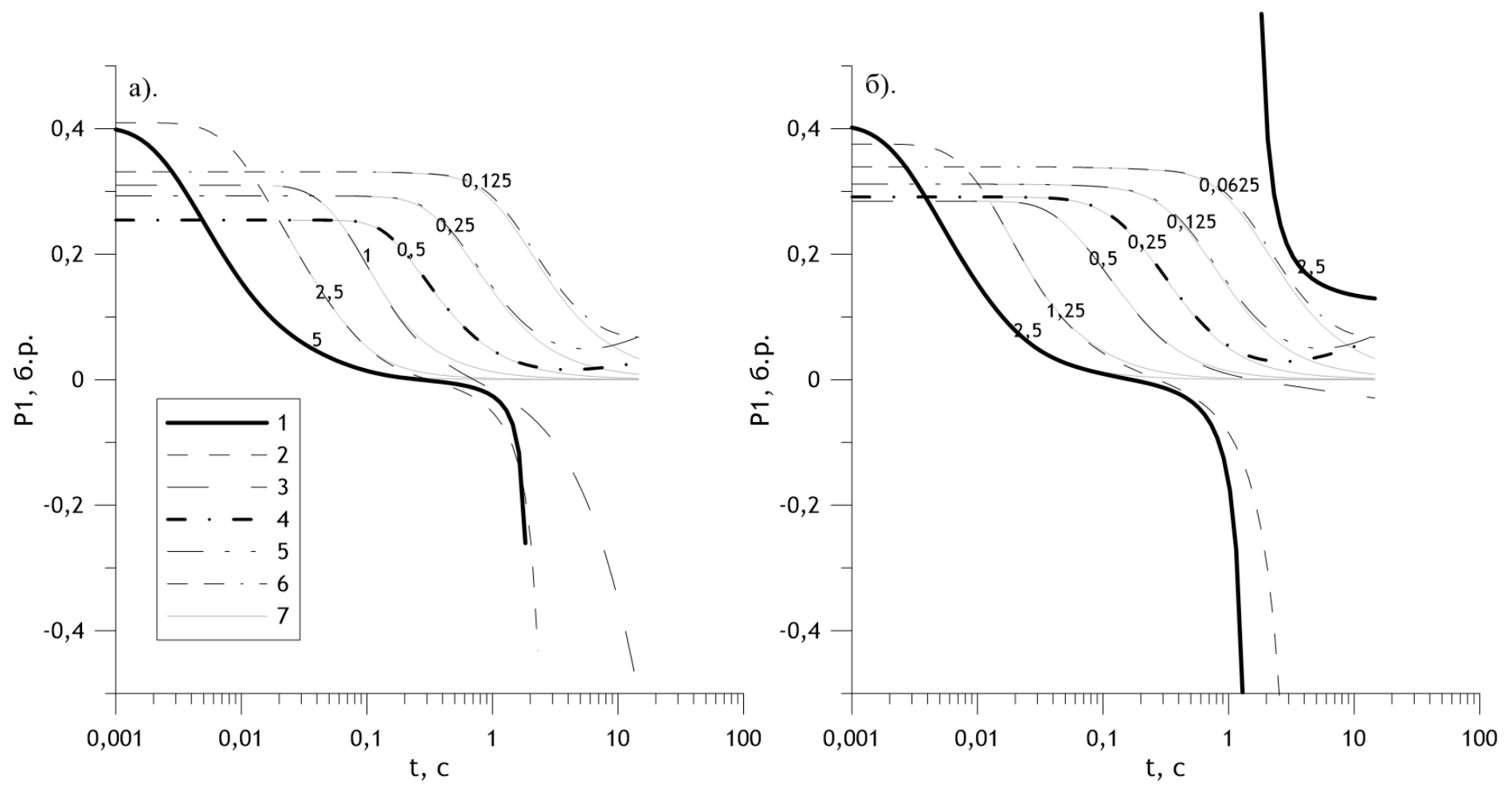

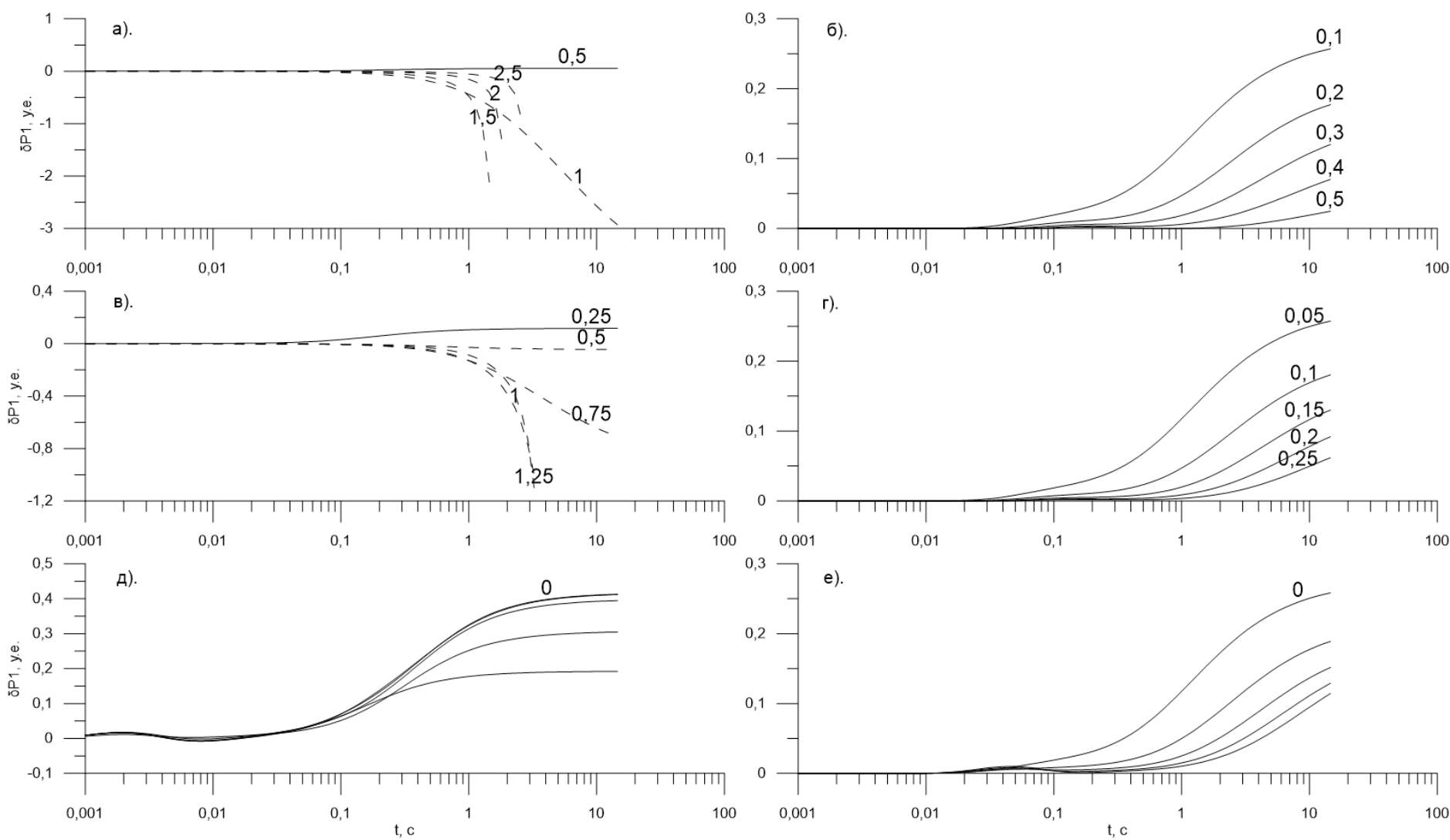

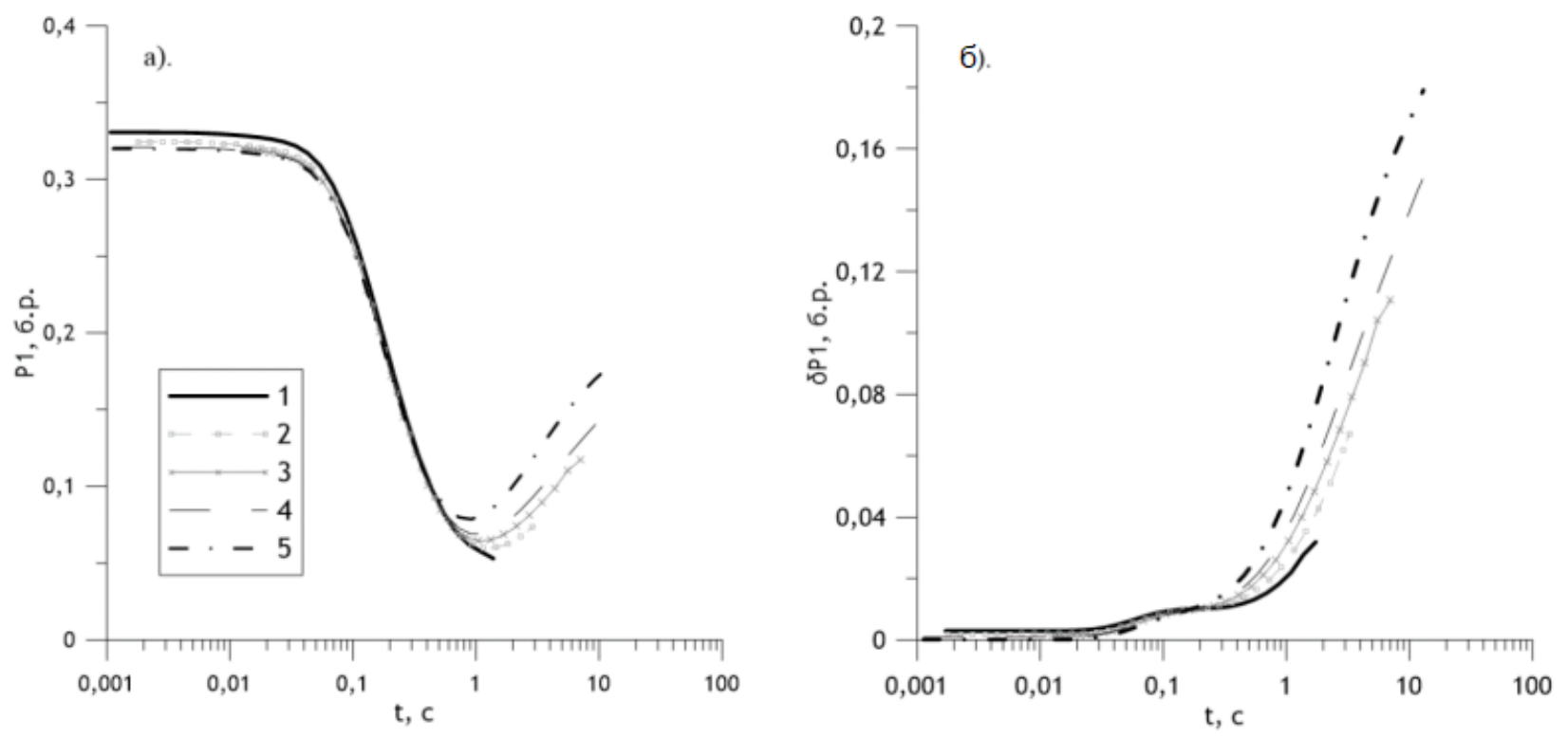